\title{
Targeting the HGF/C-MET pathway: stromal remodelling in pancreatic cancer
}

\author{
Srinivasa P. Pothula ${ }^{1,2,3}$, Zhihong Xu' ${ }^{1,2,3}$, David Goldstein ${ }^{2}$, Neil Merrett ${ }^{2}$, Romano \\ C. Pirola ${ }^{1,2,3}$, Jeremy S. Wilson ${ }^{1,2,3}$ and Minoti V. Apte ${ }^{1,2,3}$ \\ ${ }^{1}$ Pancreatic Research Group, South Western Sydney Clinical School, Faculty of Medicine, The University of New South Wales, \\ Sydney, Australia \\ ${ }^{2}$ Faculty of Medicine, The University of New South Wales, Sydney, Australia \\ ${ }^{3}$ Ingham Institute for Applied Medical Research, Liverpool, NSW, Australia
}

Correspondence to: Minoti V. Apte, email: m.apte@unsw.edu.au

Keywords: HGF/C-MET pathway, pancreatic cancer, stromal-tumor interactions, pancreatic stellate cells, orthotopic model

Received: May 09, $2017 \quad$ Accepted: August 23, $2017 \quad$ Published: September 11, 2017

Copyright: Pothula et al. This is an open-access article distributed under the terms of the Creative Commons Attribution License 3.0 (CC BY 3.0), which permits unrestricted use, distribution, and reproduction in any medium, provided the original author and source are credited.

\section{ABSTRACT}

Stromal-tumor interactions in pancreatic cancer (PC) impact on treatment outcomes. Pancreatic stellate cells (PSCs) produce the collagenous stroma of PC and interact with cancer cells to facilitate disease progression. A candidate growth factor pathway that may mediate this interaction is the hepatocyte growth factor (HGF)/ C-MET pathway. HGF is produced by PSCs and its receptor C-MET is expressed on pancreatic cancer cells. We studied the effects on PC progression of inhibiting the HGF/ C-MET pathway in the presence and absence of a representative chemotherapeutic agent, gemcitabine. Using an orthotopic model of PC we have shown that "triple therapy" (inhibition of both HGF and C-MET combined with gemcitabine) resulted in the greatest reduction in tumor volume compared to each of the treatments alone or in dual combinations. Importantly, metastasis was virtually eliminated in mice receiving triple therapy. Our in vivo findings were supported by in vitro studies showing that the increase in cancer cell proliferation and migration in response to PSC secretions was significantly inhibited by the triple regimen. Our studies suggest that a combined approach, that targets tumor cells by chemotherapy while inhibiting specific pathways that mediate stromal-tumor interactions, may represent a novel therapeutic strategy to improve outcomes in PC.

\section{INTRODUCTION}

Around 338000 new cases of pancreatic cancer (PC) are diagnosed worldwide each year and this devastating disease is set to become the second leading cause of cancer related deaths in the next decade [1]. Thus, there is an urgent need to develop new therapies to tackle this disease. PC is characterized by pronounced desmoplasia or dense collagenous stroma, which is now well acknowledged to have an intrinsic role in PC progression [2-4]. Our Group has demonstrated that this collagenous stroma is produced by activated pancreatic stellate cells (PSCs) [5]. Several preclinical studies have reported a close bidirectional interaction between pancreatic cancer cells and PSCs [6-10] which facilitates pancreatic cancer progression as evidenced by increased tumor growth as well as metastasis [7, 10-15].

Identifying the factors mediating the observed interaction between PSCs and PC cells may provide insights into novel therapeutic targets in PC $[3,15]$. A candidate factor that has received some attention in recent years is the hepatocyte growth factor (HGF), which has been shown to have a role in the progression of PC [16, 17], particularly with respect to stromal-tumor interactions $[14,18]$. We have demonstrated that HGF is secreted by cancer-associated human PSCs (hPSCs) $[14,19]$. Binding of HGF to its transmembrane cell surface receptor c-MET, which is expressed on cancer cells activates several intracellular cell-signalling pathways that play a pivotal role in cancer cell proliferation and migration. We have also demonstrated that c-MET is present on the surface of endothelial cells, which potentiate PSC-endothelial cell interaction thus indicating a role in angiogenesis, and a consequent influence on metastatic spread [19]. HGF/cMET binding has been reported to stimulate further production of HGF by mesenchymal cells, resulting in the formation of a feed-forward loop [20, 21]. Our recent 
work has shown that this pathway plays a critical role in cancer cell and endothelial cell functions [14, 19].

Using an orthotopic model of PC produced by injecting a mixture of cancer cells and cancerassociated human PSCs (hPSCs) into mouse pancreas [14], we recently published the effects of HGF inhibition (using a specific neutralizing antibody AMG102) and a representative chemotherapeutic agent, gemcitabine, as single agents and in combination, on PC progression. Effect of HGF inhibition was equivalent to gemcitabine in reduction of tumor volume but had a significantly greater effect on reducing metastasis. Indeed, gemcitabine alone failed to prevent metastasis, paralleling the clinical experience of patients receiving adjuvant gemcitabine developing metastases during treatment. We also observed that when gemcitabine was combined with HGF inhibition, the anti-metastatic effect of the latter was lost [14]. This may be a consequence of a gemcitabine-induced predisposition to increased stemness and aggressiveness of cancer cells, as has been shown by several other previous studies [14, 22-25]. However, another possible reason is that modulating only one arm (i.e. HGF) of the HGF/c-MET pathway, may not be sufficient to achieve an optimal anti-metastatic response.

In view of the above, it was of interest to determine the effects on PC of targeting both the ligand and its receptor (HGF and c-MET respectively), in the presence and absence of gemcitabine. The aim of the current studies was to determine the effects of $i$ ) HGF neutralizing antibody AMG102, ii) a small molecule inhibitor for c-MET (Compound-A) and iii) the chemotherapeutic agent gemcitabine, alone or in dual and triple combinations on PC progression, using both in vivo and in vitro approaches.

\section{RESULTS}

\section{In vivo studies}

\section{Effect of HGF/c-MET inhibition \pm gemcitabine on tumor volume}

AMG102, compound-A, and gemcitabine as single agents significantly inhibited tumor growth when compared with IgG treated animals (Figure 1). Confirming our previously published results, HGF inhibition was as effective as gemcitabine in reducing tumor volumes in our model. Dual treatments did not exert any additive or synergistic effects on tumor volume reduction compared to single agents. However, the greatest reduction in tumor volume (to $17.9 \pm$ $2.2 \%$ of control mice receiving IgG treatment) was seen in the group of mice that received triple therapy (HGF inhibition + c-MET inhibition + gemcitabine).

\section{Effect of HGF/c-MET inhibition \pm gemcitabine on tumor metastasis}

Mice treated with AMG102 or Compound-A as single agents and in dual combinations exhibited significantly reduced metastasis when compared to mice receiving IgG (Figure 2 and Table 1). Mice treated with gemcitabine as a single agent or in combination with AMG102 or Compound-A displayed some reduction in metastasis but this change was not statistically significant when compared to IgG treated mice. In contrast, in mice receiving triple therapy, there was a virtual elimination of metastasis with only one mouse in the group displaying a solitary metastatic nodule in the liver (Figure 2 and Table 1). Metastatic score was calculated as number of visible nodules per site (liver kidney, retroperitoneum,

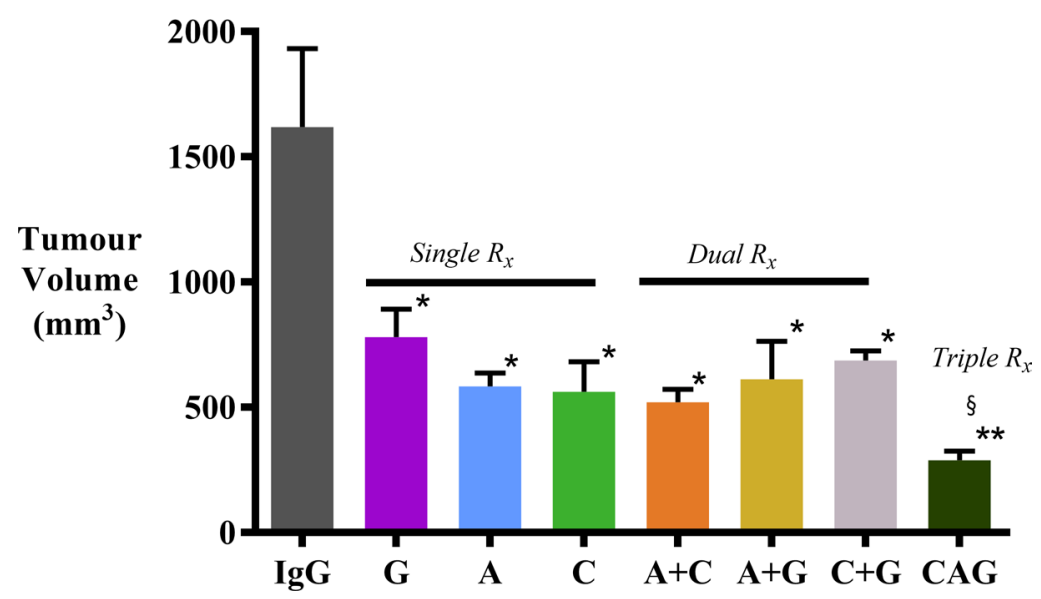

Figure 1: Effect of treatments on pancreatic tumor volumes. Pancreatic tumor volumes were reduced to a similar extent by AMG102, compound-A and gemcitabine, whether administered as single agents or in dual combinations, compared to tumors in IgG treated (control) animals ( ${ }^{*} p<0.005 \mathrm{vs} \mathrm{IgG;} n=7$ /group). However, the greatest reduction of tumor volume was observed in mice treated with triple therapy $\left({ }^{\S} p<0.05\right.$ vs G; ${ }^{*}$ p p $<0.0001$ vs IgG; $n=7 /$ group). Study Groups: Control group (IgG/vehicle control). AMG102 - A, Compound-A (small molecule c-MET inhibitor)- C, Gemcitabine - G, AMG102 + Compound-A (A+C), AMG102 + gemcitabine (A+G), c-MET inhibitor + gemcitabine $(\mathrm{C}+\mathrm{G}), \mathrm{AMG} 102+\mathrm{c}-\mathrm{MET}$ inhibitor + gemcitabine (Triple therapy or CAG). 
bowel and diaphragm) $\mathrm{x}$ number of mice and expressed as $\%$ of control score in IgG treated mice.

\section{Histological characterization of primary tumors}

\section{Effect of treatments on cancer cell numbers}

Morphometric analysis of tumor sections immunostained for cytokeratin allowed calculation of cancer cell density in tumors from each treatment group (expressed as number of cytokeratin positive cells $/ \mathrm{mm}^{2}$ ). AMG102 and Compound-A treatments both as single agents as well as in dual combinations did not result in reduction of cytokeratin expression compared to $\mathrm{IgG}$ treated tumors (Figure 3 ). However, Gemcitabine alone or in combination with AMG102 or compound-A significantly reduced cytokeratin positive cells compared to IgG treated tumors (Figure 3). Mice treated with triple therapy exhibited a reduction in cancer cell numbers to a similar extent as gemcitabine treated groups and to a significantly less extent than in control mice (IgG treated mice). This effect is not unexpected given the cytotoxic effect of gemcitabine on cancer cells in these tumors.

\section{Effect of treatments on collagen deposition}

The effect of treatments on fibrosis was assessed by software-assisted morphometric analysis on sections stained for Sirius red (which stains fibrillar collagen). AMG102 treatment alone did not change collagen deposition. Tumors from mice, which received AMG102+gemcitabine exhibited significantly higher Sirius Red expression than $\mathrm{IgG}$ treated mice (Figure 4). Tumors from mice treated with gemcitabine alone, and in combination with compound-A and with triple therapy also showed an increasing trend to higher Sirius red expression than IgG control mice but these increases did not reach statistical significance.

\section{Effect of treatments on cancer stem cell and EMT markers in vivo}

The paradoxical lack of an anti-metastatic effect with gemcitabine treatment both as a single agent and in dual combination with HGF or c-MET inhibitor (Figure 2) suggested that gemcitabine treatment may be selecting out a sub-population of cancer cells, possible stem-like cells with an aggressive phenotype and increased migratory potential due to an increase in epithelial-mesenchymal transition (EMT) as occurred with our previous studies [14].

\section{i) Stem cell marker:}

Immunohistochemistry of primary tumor sections for the stem cell marker (DCLK1) demonstrated that tumors from mice treated with gemcitabine alone, or in dual combinations with either AMG102 or compound-A exhibited higher expression of DCLK1 (Figure 5). However, gemcitabine in combination with $\mathrm{HGF}+\mathrm{c}-$ MET inhibition (triple therapy) resulted in a significant reduction in DCLK1 expression back to control levels.

\section{ii) EMT marker:}

Immunohistochemistry of primary tumor sections for the EMT marker (TWIST) demonstrated that tumors from mice treated with gemcitabine alone, or in combination with AMG102 exhibited significantly higher expression of TWIST compared to IgG treated control mice (Figure 6A). Although the mice receiving gemcitabine in combination with compound-A $(\mathrm{C}+\mathrm{G})$ as well as mice in the triple therapy groups demonstrated a trend to an increase in TWIST expression, this did not reach statistical significance. Immunoblotting tumor homogenates for e-cadherin showed a trend to a reduction in e-cadherin expression in tumors from mice treated with gemcitabine. This reduction was

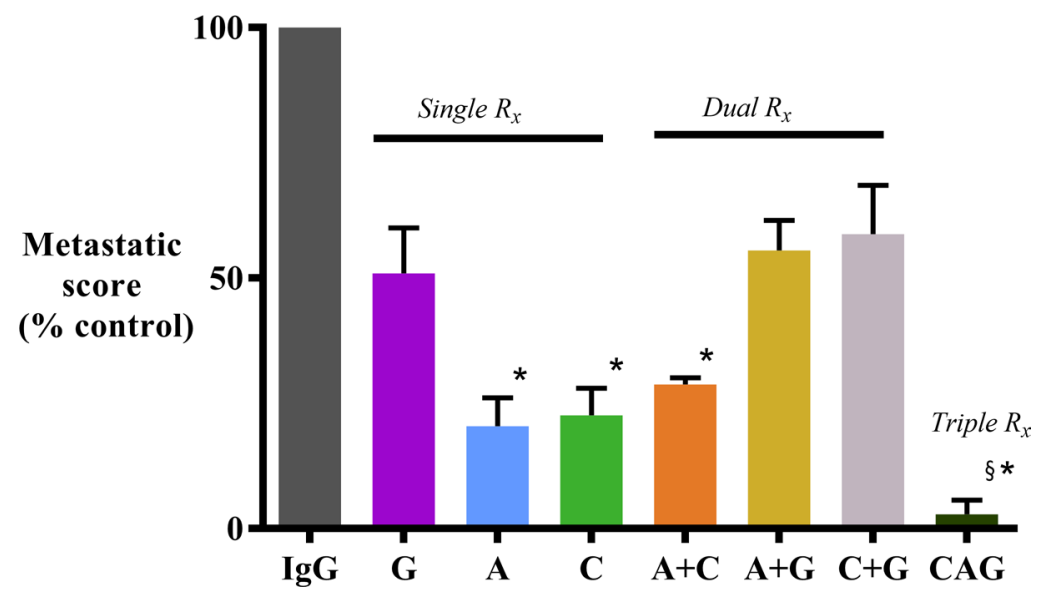

Figure 2: Effect of treatments on metastatic spread. Mice treated with AMG102 and Compound-A (both as single agents and in combination) exhibited significantly reduced metastatic spread to the organs/regions depicted in the Table 1 when compared to IgG treated mice. In contrast, decrease in metastasis was not statistically significant in mice treated with gemcitabine as single agent or in dual combinations. Interestingly, mice treated with triple therapy exhibited virtual absence of metastasis. $\left({ }^{*} p<0.05 ;{ }^{\circledR} p<0.001 \mathrm{vs} \mathrm{IgG,} n=7 /\right.$ group). Study Groups: Control group (IgG/vehicle control). AMG102 - A, Compound-A (small molecule c-MET inhibitor)- C, Gemcitabine - G, AMG102 + Compound-A (A+C), AMG102 + gemcitabine (A+G), c-MET inhibitor + gemcitabine (C+G), AMG102+c-MET inhibitor + gemcitabine (Triple therapy or CAG). 
Table 1: Metastatic nodules noted in number of mice treated in our orthotopic model in various sites ( $n=7$ mice/group)

\begin{tabular}{lcccccccc}
\hline & IgG & A & G & C & C+A & A+G & C+ G & $\mathbf{C}+\mathbf{A}+\mathbf{G}$ \\
\hline Liver & 7 & 2 & 6 & 3 & 2 & 5 & 6 & 1 \\
Kidney & 4 & 0 & 2 & 1 & 1 & 3 & 3 & 0 \\
Bowel & 7 & 2 & 3 & 1 & 2 & 4 & 3 & 0 \\
Retro-peritoneum & 7 & 2 & 3 & 1 & 2 & 2 & 4 & 0 \\
Diaphragm & 6 & 1 & 2 & 1 & 2 & 3 & 2 & 0 \\
\hline TOTAL & $\mathbf{3 1}$ & $\mathbf{7}$ & $\mathbf{1 6}$ & $\mathbf{7}$ & $\mathbf{9}$ & $\mathbf{1 7}$ & $\mathbf{1 8}$ & $\mathbf{1}$ \\
\hline
\end{tabular}

statistically significant in tumors from $\mathrm{C}+\mathrm{G}$ group when compared with tumors from triple therapy group (Figure 6B).

\section{Effect of treatments on tumor angiogenesis in vivo}

As HGF is known to have an angiogenic effect in several other cancers [26, 27], tumor sections were stained for the endothelial cell marker CD31, an indicator of neo-angiogenesis. Morphometric analysis of stained sections indicated a modest but statistically significant decrease in CD31 expression in tumors from mice treated with AMG102 compared to IgG treated tumors $(82.63 \pm$ $4.8 \%$ of $\mathrm{IgG}$ treated mice as control). These results are in keeping with our previous studies and concur with the proposed angiogenic role of HGF in cancers [14]. These data also support our previously published in vitro results, which demonstrated that HGF inhibition (using AMG102) directly reduced proliferation and migration of human microvascular endothelial cells, HMEC-1 [19]. However, c-MET inhibition alone or in combination with AMG102 did not affect CD31 expression $(91 \pm 6.2 \%$ and $87.6 \pm$ $7 \%$ respectively). Gemcitabine treatment as a single agent or in dual or triple combination also did not result in any significant changes in CD31 expression (88.3 $\pm 7.4 \%, 95.5$ $\pm 5 \%, 96 \pm 6.4 \%$ and $89 \pm 6 \%$ respectively).

\section{In vitro studies}

\section{Role of HGF/c-MET in PSC-PC cell interactions in vitro}

The role of the HGF/c-MET pathway in PSC-cancer cell interactions was determined by performing indirect co-culture experiments and assessing the effects of PSC secretions on cancer cell functions in the presence or absence of $\mathrm{HGF} / \mathrm{c}-\mathrm{MET}$ inhibitors and/or gemcitabine.

i) Effect of HGF/c-MET inhibition \pm gemcitabine on cancer cell proliferation in vitro

hPSC secretions with known amounts of HGF (2000pg/mL) induced AsPC-1 proliferation compared to controls i.e. cancer cells incubated with co-culture medium alone, confirming our previously published studies [14, 28]. This hPSC-induced cancer cell proliferation was unchanged by exposure of cells to hPSC secretions pre-treated with AMG102 or when cancer cells were treated with c-MET inhibitor alone. However, hPSC-induced cancer cell proliferation was significantly inhibited by the combination of AMG102+c-MET inhibitor. Gemcitabine alone and in dual combinations also significantly reduced cancer cell proliferation. The greatest reduction in hPSC-induced AsPC-1 proliferation was observed with triple therapy (HGF inhibition + c-MET inhibition + gemcitabine) (Figure 7A).

\section{ii) Effect of HGF/c-MET inhibition \pm gemcitabine on cancer migration in vitro}

AsPC-1 cell migration was induced upon exposure to hPSC secretions, in agreement with our previously published reports $[14,28]$. This induction of AsPC-1 migration was prevented by each of the treatments with the greatest reduction observed in AsPC1 cells exposed to the triple treatment $(\mathrm{HGF}$ inhibition $+\mathrm{c}-\mathrm{MET}$ inhibition + gemcitabine) (Figure 7B).

iii) Effect of HGF/c-MET inhibition \pm gemcitabine on cancer cell apoptosis in vitro

For these studies, AsPC-1 cells were first subjected to serum starvation to induce apoptosis of the cells. In the presence of IgG treated hPSC secretions, AsPC-1 apoptosis induced by serum starvation was inhibited albeit to a modest level ( $94 \pm 1 \%$ of medium control). However there was no effect on such apoptosis with HGF inhibition alone, gemcitabine alone or in their dual combination. Interestingly, AsPC1 apoptosis induced by serum starvation was modestly but significantly increased further in the presence of c-MET inhibition as a single agent or in dual combination with AMG102 or with gemcitabine $(111 \pm 2.5 \%, 108 \pm 1.8 \%, 110 \pm 3.5 \%$ of medium control respectively). Importantly, this pro-apoptotic effect persisted in cells treated with the triple combination $(105.3 \pm 2 \%)$.

iv) Signalling pathways mediating the effects of $\mathrm{HGF} / \mathrm{c}-$ MET inhibition on cancer cells

To determine the effects of HGF/c-MET inhibition, c-MET phosphorylation and total c-MET were examined by immunoblotting. AsPC-1 cells were exposed to i) hPSC secretions pretreated with IgG (control) or with AMG102 (HGF antibody) and ii) hPSC secretions in the presence of PHA665752 (c-MET inhibitor). Immunoblotting showed increased phosphorylated c-MET as well as total 
A
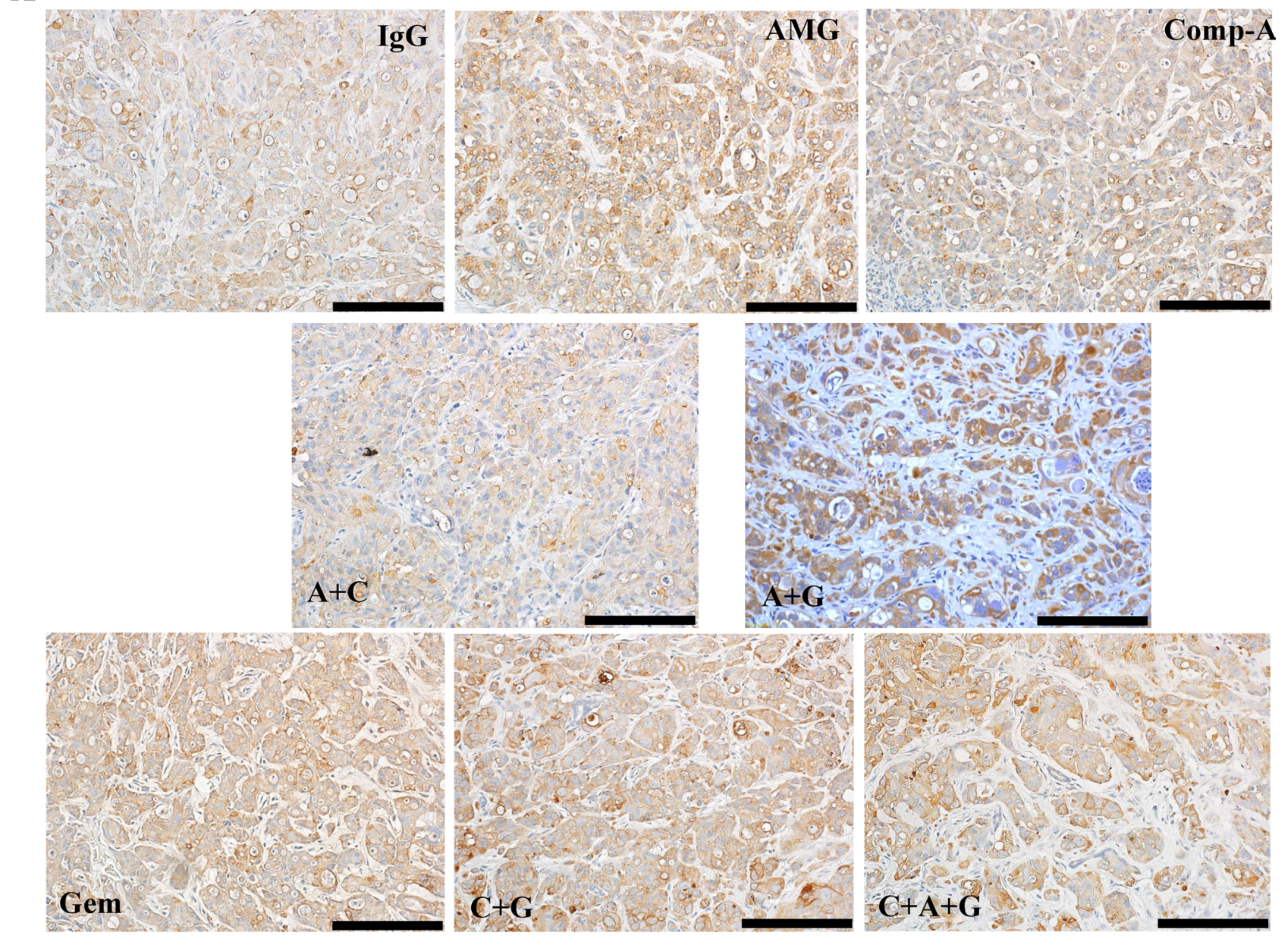

B

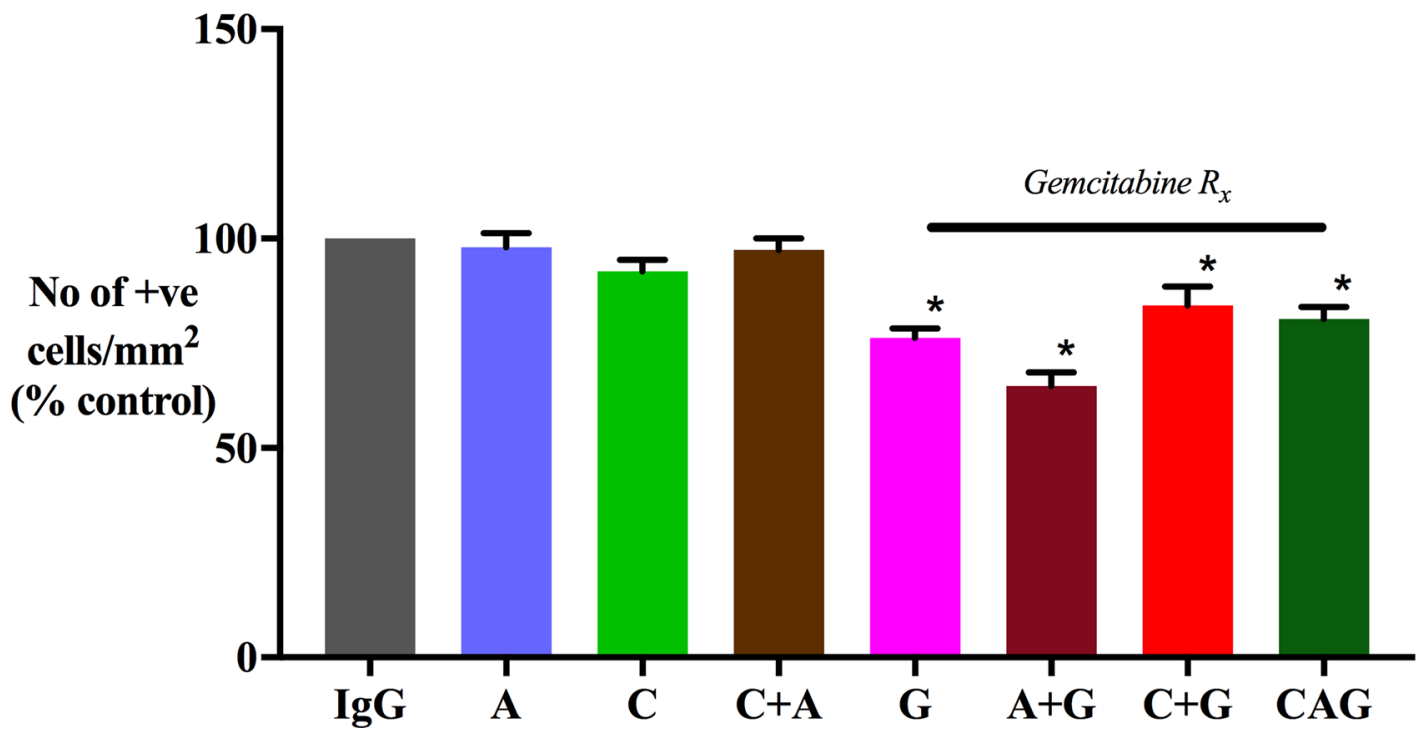

Figure 3: Effect of treatments on cancer cell density. (A) Representative images of primary tumor sections immunostained for the cancer cell marker cytokeratin (scale bar: $50 \mu \mathrm{m}$ ). (B) A bar graph depicting morphometric analysis for cancer cell density [calculated as the number of brown stained cells per unit area of tumor, and expressed as \% of control (IgG treated) tumors]. Compared to the IgG treated group, cancer cell density was significantly reduced in mice treated with gemcitabine singly and in dual or triple combinations $(* p<0.05$ vs IgG, $n=7$ mice/group), while AMG102 and compound-A as single and dual combinations failed to decrease cancer cell numbers compared to IgG controls. Study Groups: Control group (IgG/vehicle control). AMG102 - A, Compound-A (small molecule c-MET inhibitor)- C, Gemcitabine - G, AMG102 + Compound-A $(A+C)$, AMG102 + gemcitabine $(A+G)$, c-MET inhibitor + gemcitabine $(C+G), A M G 102+$ c-MET inhibitor + gemcitabine (Triple therapy or CAG) 
A
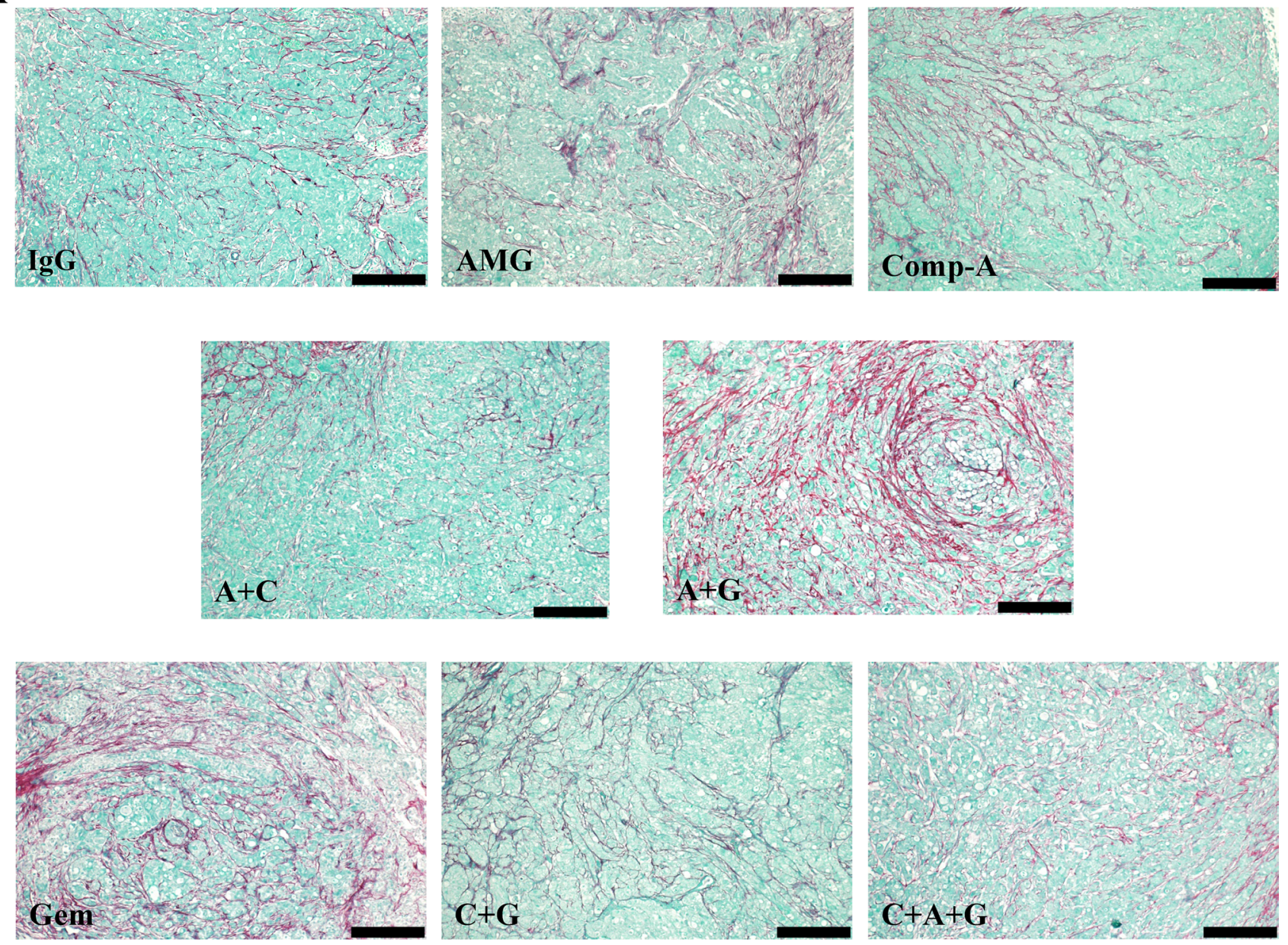

B

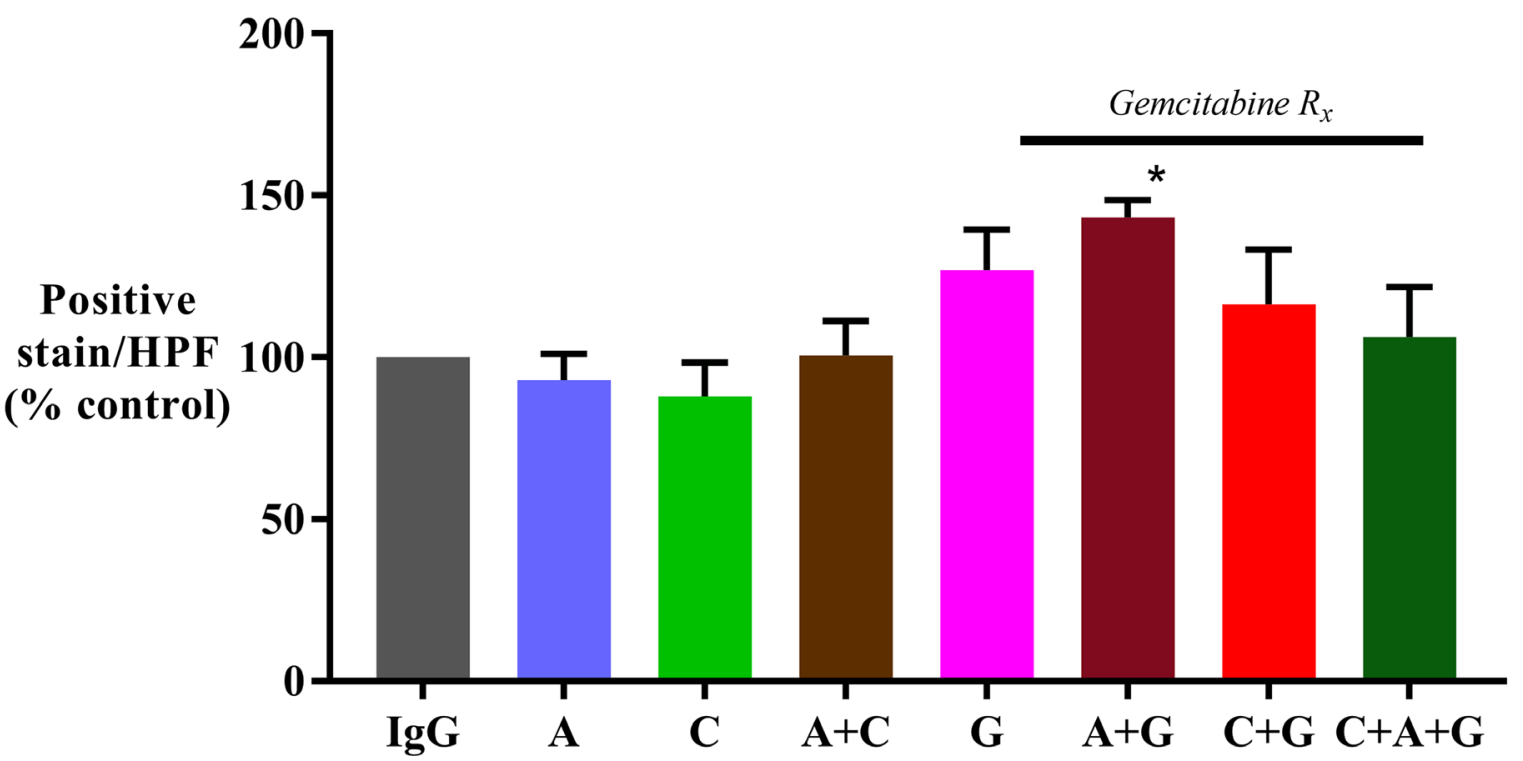

Figure 4: Effect of treatments on collagen deposition. (A) Representative images of tumor sections stained for Sirius red (marker for collagen deposition) (scale bar: $200 \mu \mathrm{m}$ ). (B) A bar graph depicting the morphometric analysis for collagen deposition in our orthotopic model. Fibrillar collagen deposition was increased in animals treated with gemcitabine + AMG102 when compared to any other treatment $\left({ }^{*} p<0.05\right.$ vs IgG, AMG102 and compound-A). Study Groups: Control group (IgG/vehicle control). AMG102 - A, Compound-A (small molecule c-MET inhibitor)- C, Gemcitabine - G, AMG102 + Compound-A (A+C), AMG102 + gemcitabine (A+G), c-MET inhibitor + gemcitabine $(\mathrm{C}+\mathrm{G}), \mathrm{AMG102}+\mathrm{c}-\mathrm{MET}$ inhibitor + gemcitabine (Triple therapy or CAG) 
A

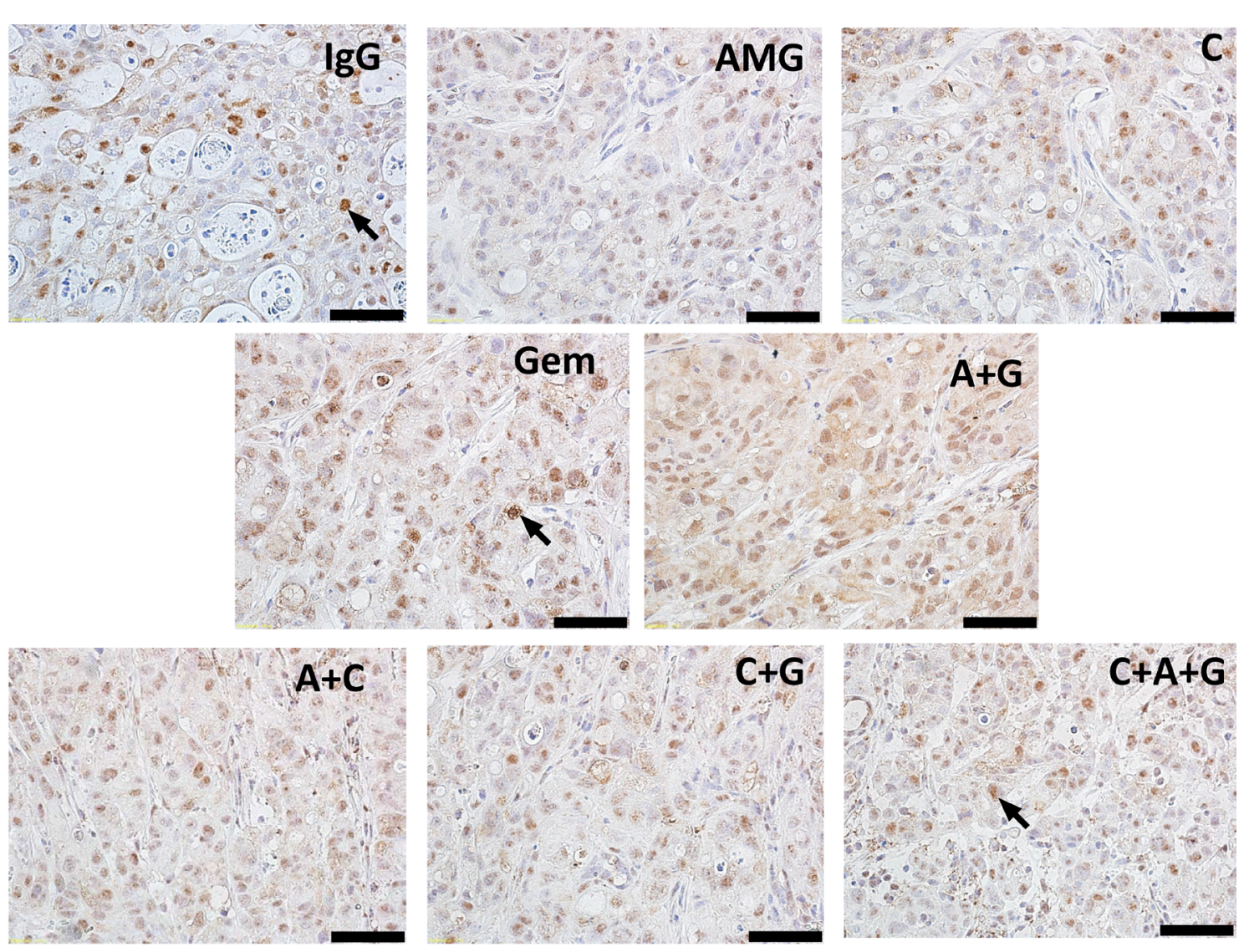

B

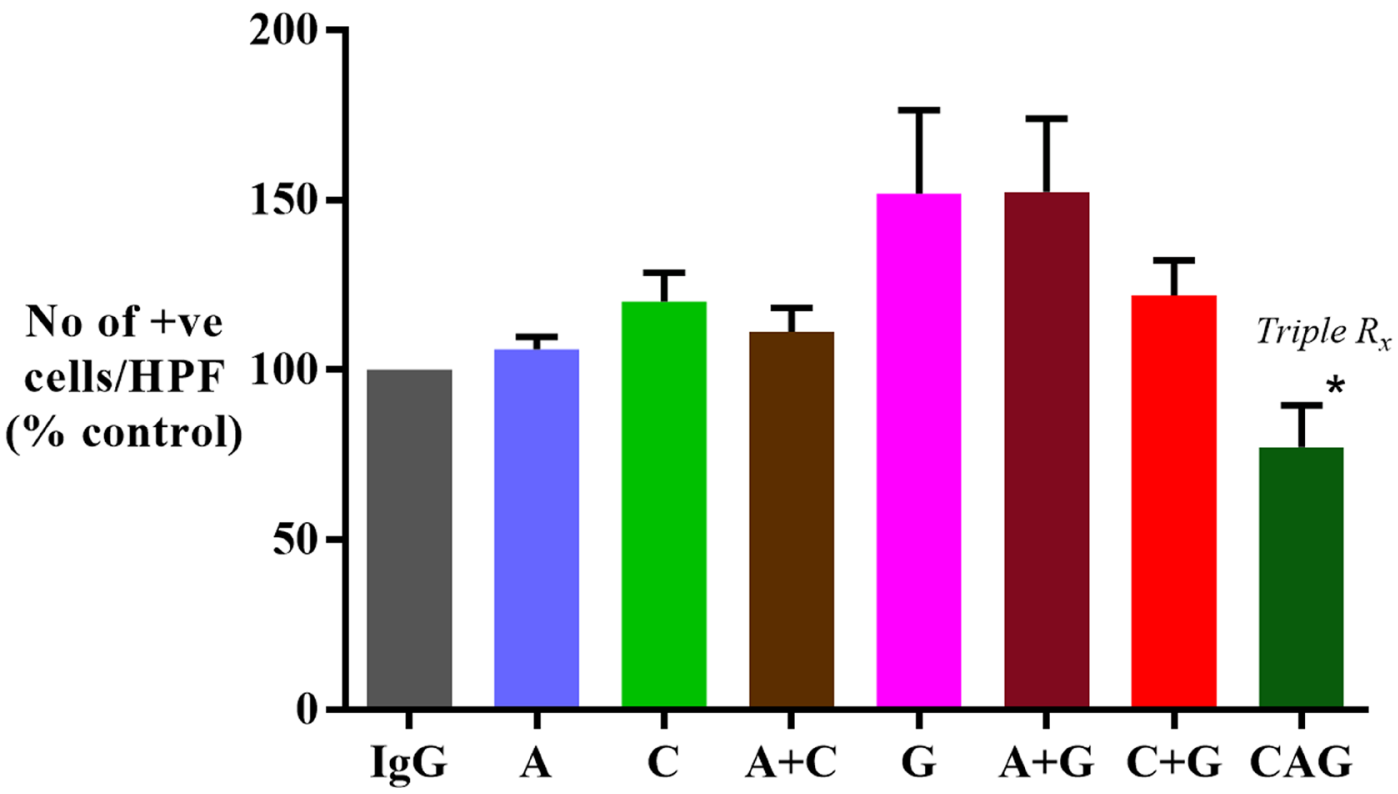

Figure 5: Effect of treatments on DCLK1 (stem cell marker) expression. (A) Representative images of tumor sections immunostained for the stem cell marker DCLK1. Arrows indicate representative positive cells. (scale bar: $100 \mu \mathrm{m})$. (B) Graph depicting morphometric analysis for DCLK1 positive cells (number of brown positive cells per HPF, and expressed as \% of control, IgG treated tumors). Compared to IgG treated tumors, there is a trend towards an increased number of cells expressing DCLK1 in gemcitabine treated mice when used as a single agent $(G)$ or in combination with AMG102 (A+G). However this increase did not reach statistical significance. Notably, there is a significant reduction in expression of DCLK1 in tumors of mice treated with triple therapy when compared with other treatment involving gemcitabine as well as compound-A as single agent ( ${ }^{*} p<0.02$ vs G, A+G, C+G, C; $n=7$ mice/group). Study Groups: Control group (IgG/vehicle control). AMG102 - A, Compound-A (small molecule c-MET inhibitor)- C, Gemcitabine - G, AMG102 + Compound-A $(\mathrm{A}+\mathrm{C}), \mathrm{AMG102}+$ gemcitabine $(\mathrm{A}+\mathrm{G}), \mathrm{c}-\mathrm{MET}$ inhibitor + gemcitabine $(\mathrm{C}+\mathrm{G}), \mathrm{AMG} 102+\mathrm{c}-\mathrm{MET}$ inhibitor + gemcitabine (Triple therapy or $\mathrm{CAG}$ ) 
A (i)

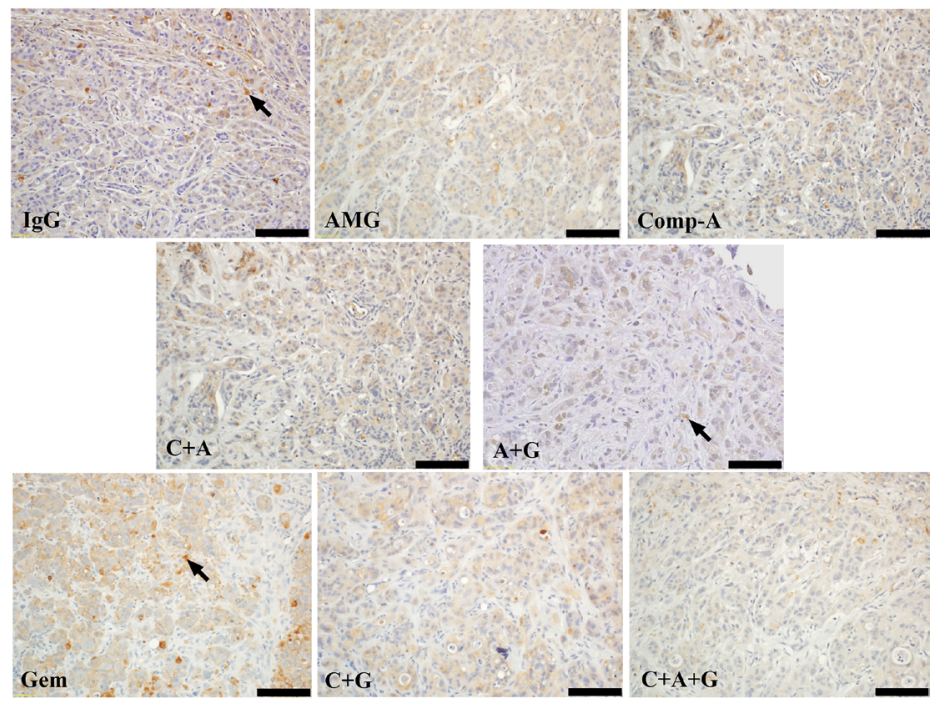

(ii)

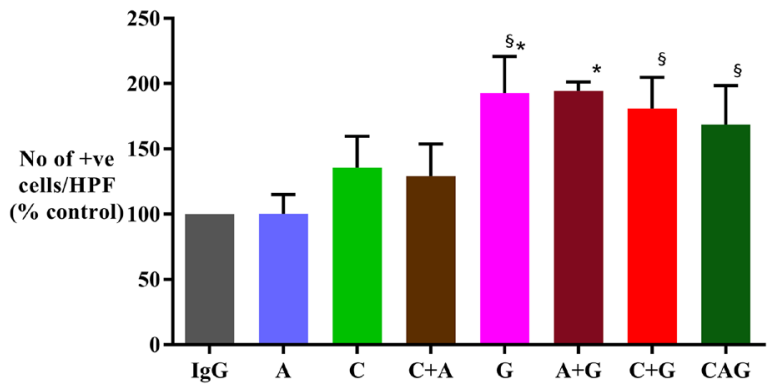

B (i)

E-cadherin
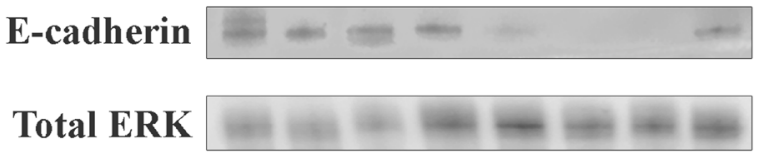

(ii)

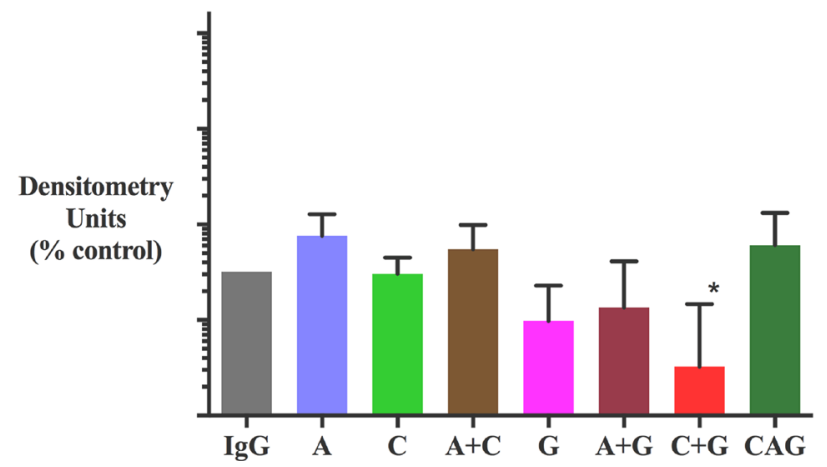

Figure 6: Effect of treatments on epithelial-mesenchymal transition (EMT). (A) Effect of treatments on TWIST (EMT marker) expression (i) Representative images of tumor sections immunostained for the EMT marker TWIST. Arrows indicate representative positive cells. (scale bar: $100 \mu \mathrm{m}$ ). (ii) Graph depicting morphometric analysis for TWIST positive cells (EMT marker) [number of brown positive cells per unit area of tumor, and expressed as \% of control (IgG treated tumors)]. Compared to IgG treated tumors, the number of cells undergoing EMT was significantly increased by gemcitabine treatment both as a single agent (G) and in combination with AMG102 $(A+G)$. Gemcitabine alone and in combination with compound-A as well as in triple therapy increased EMT when compared to AMG102 treated tumors $\left({ }^{*} p<0.05\right.$ vs IgG, ${ }^{\S} p<0.05$ vs AMG102, $n=7$ mice/group). (B) Effect of treatments on E-cadherin (EMT marker) expression. (i) Representative immunoblots for e-cadherin (top panel) in tumor homogenates from the orthotopic model. The bottom panel shows immunoblots for total ERK, used as a loading control. (ii) Bar graphs showing densitometry results [corrected for respective loading controls and expressed as \% of control in $\log _{10}$ scale ( $\operatorname{IgG}$ treated tumors)]. Compared to control tumors, expression of e-cadherin is significantly reduced in mice treated with $\mathrm{C}+\mathrm{G}$. However this reduction is not seen in tumors from mice that received triple therapy (* $\$ p<0.05$ vs A, A+C, CAG, $n=7$ mice/ treatment group).Study Groups: Control group (IgG/vehicle control). AMG102 - A, Compound-A (small molecule c-MET inhibitor)- C, Gemcitabine - G, AMG102 + Compound-A (A+C), AMG102 + gemcitabine (A+G), c-MET inhibitor + gemcitabine $(\mathrm{C}+\mathrm{G}), \mathrm{AMG102}+\mathrm{c}-\mathrm{MET}$ inhibitor + gemcitabine (Triple therapy or CAG). 
c-MET in cancer cells exposed to hPSC secretions for 10 minutes. Phosphorylation of cMET was significantly reduced by c-MET inhibitor but not by HGF inhibition (Figure 8A), while expression of total c-MET did not show any significant reduction with either AMG102 or c-MET inhibitor.
Downstream ERK1/2 activation was also examined by immunoblotting. Increased phosphorylation of ERK was observed in cancer cells exposed to hPSC secretions for 15 minutes. This effect was reversed in the presence of the HGF antibody as well as the c-MET inhibitor (Figure 8B).

A

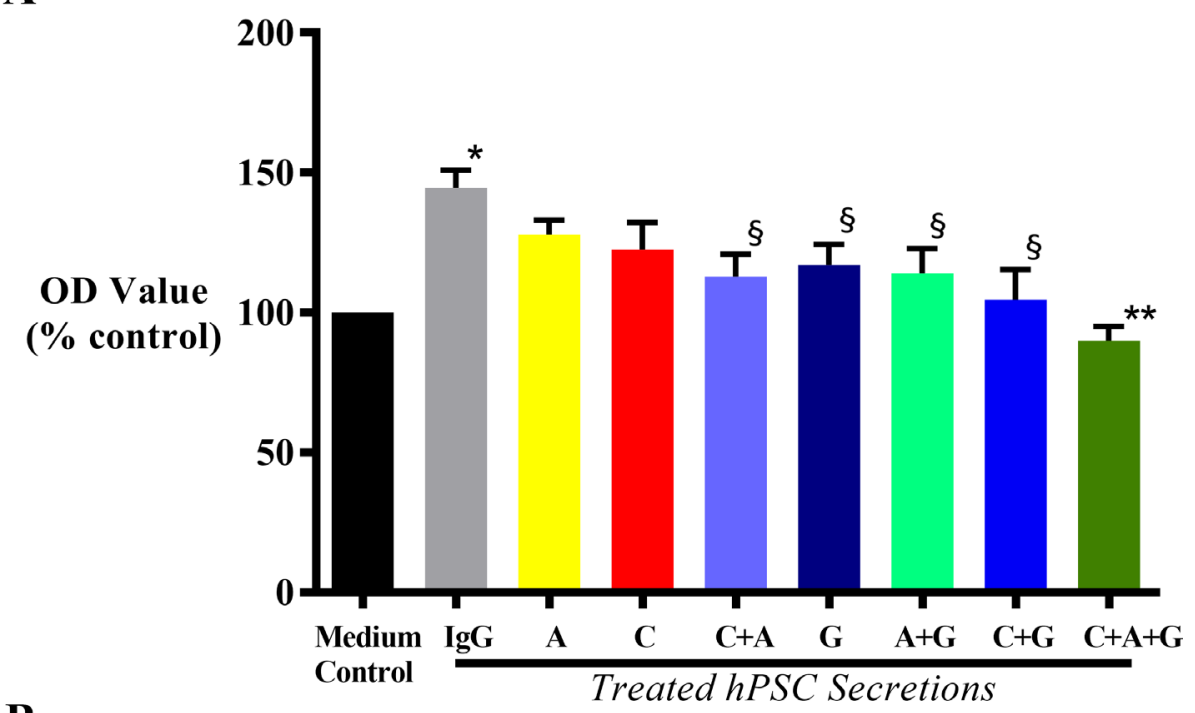

B

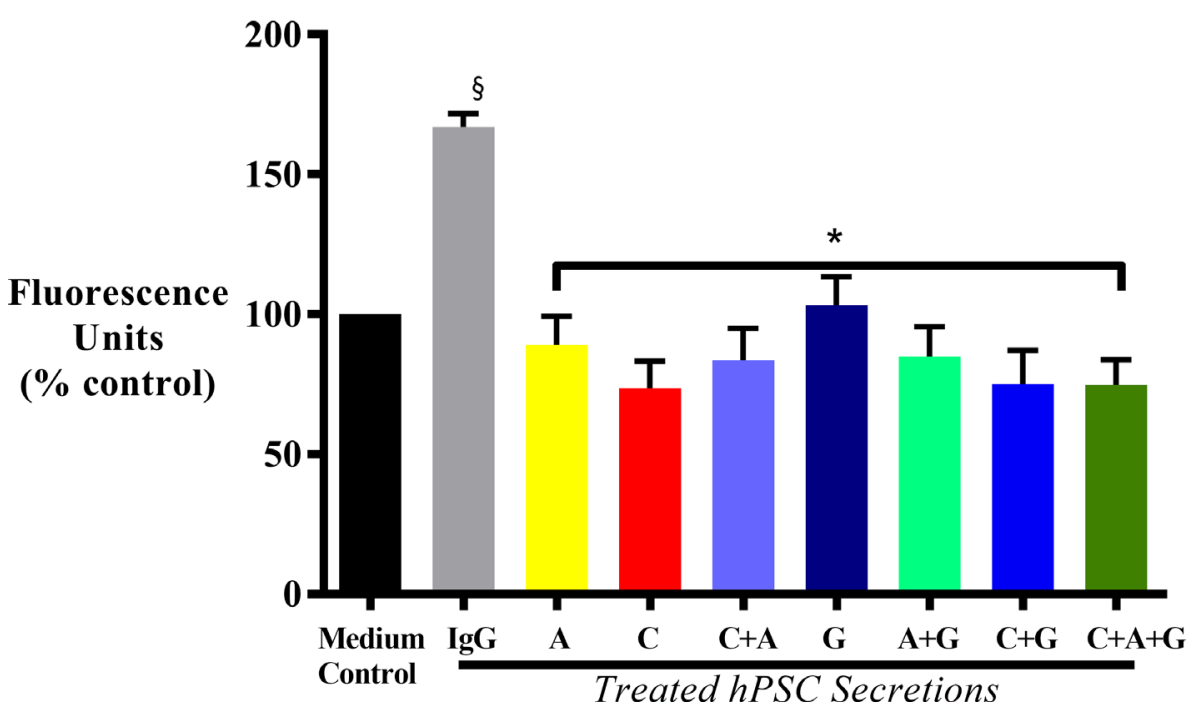

Figure 7: Effect of treatments on cancer cell proliferation and migration. (A) Effect on cancer cell proliferation in response to treatment with HGF inhibitor AMG102 (A), c-MET inhibitor (C) or gemcitabine (G), alone or in dual or triple combination in vitro. AsPC1 cells were incubated with medium control or IgG treated hPSC secretions, or hPSC secretions pre-treated either with AMG102, or c-MET inhibitor, or gemcitabine as single agents, or in dual or triple combinations. Compared to control, hPSC secretions (IgG group) significantly induced AsPC-1 proliferation ( ${ }^{*} p<0.0001$ vs medium control). This hPSC-induced AsPC-1 proliferation remained unchanged with either HGF (A) or c-MET inhibition (C) alone; but significantly inhibited with gemcitabine (G) as single agent and in any other combination $\left({ }^{\S} p<0.02\right.$ vs $\left.\operatorname{IgG}\right)$. Similar reduction was also observed with HGF and c-MET inhibition as a dual combination $\left({ }^{\S} p<0.02 \mathrm{vs} \operatorname{IgG}\right)$. However, the greatest reduction was observed with triple therapy $(\mathrm{C}+\mathrm{A}+\mathrm{G})$ in the treatment $(* * p<0.0001$ vs IgG; $n=5$ separate $\mathrm{hPSC}$ preparations). (B) Effect on cancer cell migration in response to treatment with HGF inhibitor AMG102 (A), c-MET inhibitor (C) or gemcitabine $(\mathrm{G})$, alone or in dual or triple combination in vitro. AsPC-1 cells were incubated with medium control or IgG treated hPSC secretions, or hPSC secretions pre-treated either with AMG102, or c-MET inhibitor, or gemcitabine as single agents, or in dual or triple combinations. Compared to medium control, hPSC secretions (IgG group) significantly induced AsPC-1 migration ( ${ }^{\$} p<0.0001$ vs medium control). This hPSC-induced AsPC-1 migration was significantly inhibited with all the treatments $\left({ }^{*} p<0.0001 \mathrm{vs} \mathrm{IgG;} n=5\right.$ separate hPSC preparations). 


\section{DISCUSSION}

Using both in vivo and in vitro approaches, this study has provided novel evidence to indicate that stromal reprogramming (by inhibiting the HGF/c-MET pathway) combined with chemotherapy significantly reduces pancreatic cancer progression. The most effective combination was 'triple therapy' comprising a standard chemotherapeutic agent (gemcitabine), a monoclonal antibody against human HGF (AMG102) and a c-MET inhibitor. This triple therapy induced significantly greater reduction in tumor volume compared to single and dual treatments and importantly, virtually eliminated metastasis in our orthotopic model of pancreatic cancer. Our in vivo findings with triple therapy were supported by the results of our in vitro experiments showing that triple combination inhibited both cancer cell proliferation and migration to a greater extent than other treatment combinations.

Both HGF inhibition and c-MET blockade (using the small molecule c-MET inhibitor Compound-A) alone resulted in tumor reduction to a similar extent as that observed with gemcitabine. Supporting these results, are our in vitro observations whereby HGF inhibition or c-MET blockade alone inhibited cancer cell proliferation. However, dual combinations i.e HGF inhibition + c-MET blockade, HGF inhibition + gemcitabine and c-MET blockade + gemcitabine did not exhibit any additive effect in terms of tumor reduction. Our findings with c-MET blockade + gemcitabine do not agree with studies that have reported a synergistic effect between inhibition of c-MET and gemcitabine [22, 29, 30]. Notably, none of these studies have considered the role of stromal cells in their preclinical cancer models. The most recent of these studies [29] has employed both syngeneic and xenogeneic orthotopic models to demonstrate the effects of c-MET inhibition in combination with gemcitabine: However the stromal cells employed for their in vitro studies were limited to endothelial cells and vascular smooth muscle cells, and lacked the predominant source of HGF i.e. PSCs. The discrepancy between the results of these studies and our data suggests that in the presence of a continuous source of HGF secretion (i.e. PSCs) as in our study, c-MET inhibition alone may not be sufficient to significantly reduce cancer progression.

The observed reduction in tumor volumes in treated mice could be a result of reduced cancer cell proliferation as well as increased apoptosis. In our in vitro experiments, serum starvation induced apoptosis in cancer cells; however in the presence of hPSC secretions this effect was inhibited and may explain the increased tumor volumes observed in IgG treated mice in vivo. However, gemcitabine and HGF inhibition alone or in dual combination did not influence cancer cell apoptosis; hence the reduced tumor volumes in these mice could be due to reduced proliferation rather than increased apoptosis of cancer cells. Interestingly, c-MET inhibition as a single agent and in all other combinations exerted a pro-apoptotic effect which is in keeping with similar published reports in other cancers [31-33]. This could be one of the mechanisms mediating the observed reduction in tumor volume observed with c-MET inhibition in our in vivo model.

With respect to fibrosis, tumors from mice that received gemcitabine treatment as a dual combination with HGF inhibition exhibited higher fibrosis compared to all other groups confirming our previous results [14]. Tumors from other mice that received gemcitabine also showed a trend towards increased (albeit not statistically significant) fibrosis. This could possibly be due to the increased activation state of PSCs in response to the factors released by gemcitabine affected cancer cells [14].

Several studies have linked activation of c-MET signalling to phosphorylation of intracellular signalling cascades such as PI3K/AKT, MAPK/ERK [34, 35] or FAK [36] in pancreatic cancer models, leading to tumor cell invasiveness, motility and resistance to gemcitabine therapy. In the current study, we observed that the effect of c-MET inhibition resulted in downregulation of ERK1/2 signalling, which concurs with our previous observation with HGF inhibition [14]. Effects of Akt signalling were not investigated as hPSC secretions did not induce phosphorylation of Akt as we previously reported [14]. Cancer cells exposed to hPSC secretions exhibited increased activation/phosphorylation of c-MET most likely in response to HGF in the secretions. As expected, this c-MET phosphorylation was prevented in the presence of the c-MET inhibitor PHA665752, as previously reported [32, 33, 37-39].

Regarding metastatic spread in our model, a significant reduction in metastasis was observed with c-MET inhibition as a single agent, as well as in dual combination with AMG102. However this anti-metastatic effect was lost when c-MET inhibition was combined with gemcitabine treatment. These observations are similar to our previous findings [14], where the anti-metastatic effect of AMG102 was lost when combined with gemcitabine. Taken together these observations strengthen our view [14], that gemcitabine selects out a population of cancer cells with enhanced survivability and migratory potential. We examined this concept by assessing orthotopic tumors for the expression of the stem cell marker double cortin like kinase-1(DCLK1), which is known to be elevated in $\mathrm{PC}$ and is associated with increased metastatic potential of the disease $[40,41]$ and the EMT marker TWIST.

While HGF/c-MET inhibition itself did not affect stemness or EMT, gemcitabine treatment alone as well as in combination with AMG102 or c-MET inhibitor induced both stemness as well as EMT as evidenced by increased expression of DCLK1 and TWIST, and reduced e-cadherin expression in the tumors. These observations support our previous findings [14] as well as others that indicate the formation of a chemo-resistant population of cancer cells following chemotherapy [23-25]. 


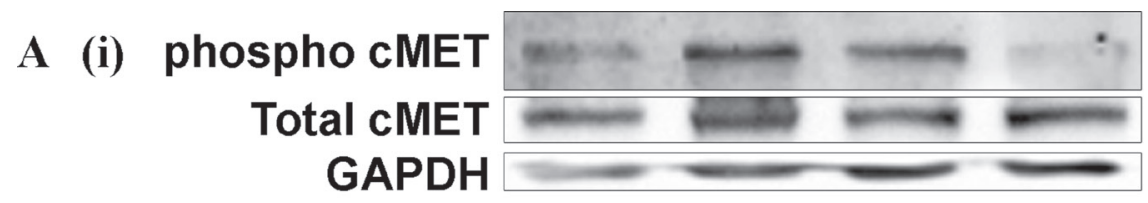

(ii)

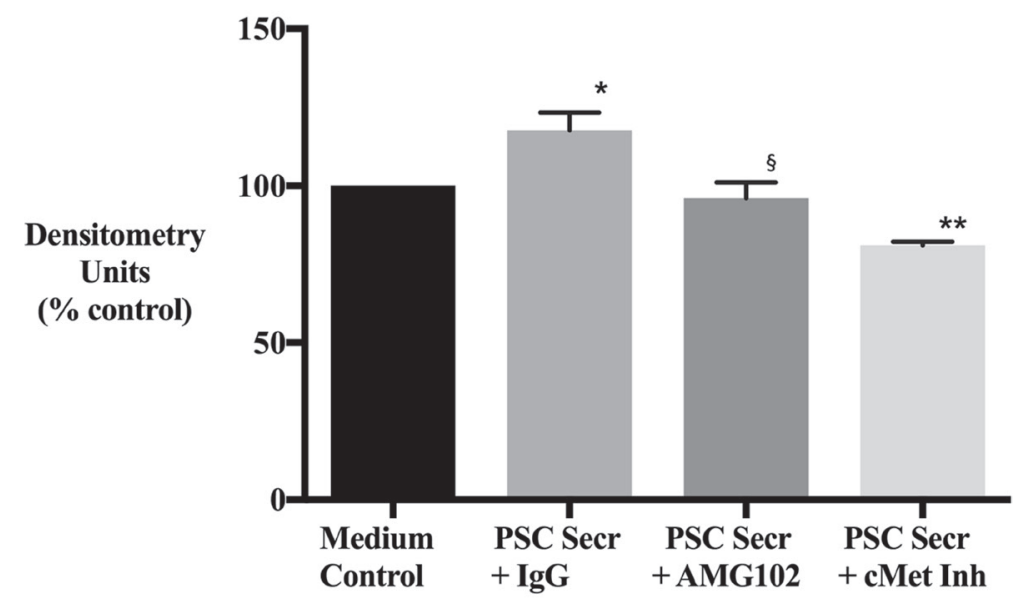

B (i)

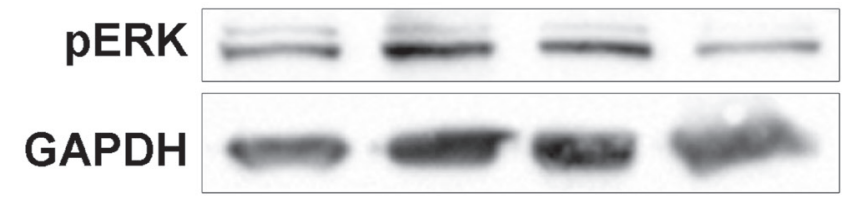

(ii)

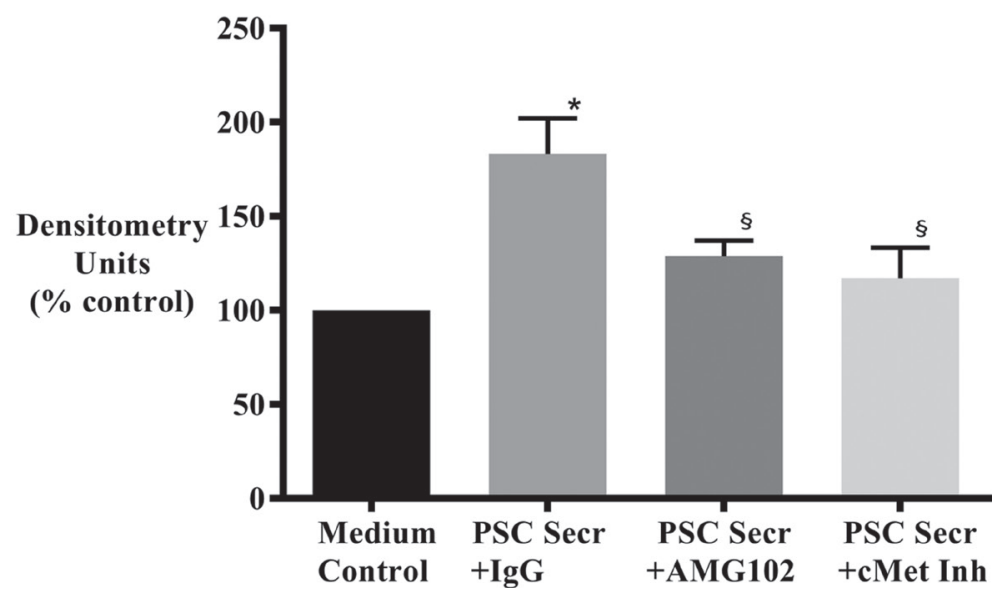

Figure 8: Effect of treatments on cancer cell signalling. (A) Cancer cell response to HGF inhibition (AMG102) and c-MET inhibition (cMet Inh) was mediated by c-MET activation. (i) Representative immunoblots for phosphorylated (top panel) and total c-MET (middle panel) in AsPC-1 cell lysates collected after exposure of cells to hPSC secretions pretreated with either IgG or AMG102 or c-MET inhibitor (c-Met Inh) for 10 minutes. The bottom most panel shows GAPDH, used as a loading control. (ii) Bar graphs showing densitometry results [corrected for respective loading controls and expressed as $\%$ of control (co-culture medium)]. Compared to medium control, hPSC secretions significantly increased phospho-c-MET but not total c-MET $\left({ }^{*} p<0.05, n=3 \mathrm{hPSC}\right.$ preparations). This hPSCinduced phosphorylation of c-MET was inhibited with AMG102 $\left({ }^{\S} \mathrm{p}<0.02 \mathrm{vs} \operatorname{Secr}+\operatorname{IgG}, n=3 \mathrm{hPSC}\right.$ preparations $)$ as well as c-MET inhibition (** $p<0.01$ vs Secr+IgG, $n=3 \mathrm{hPSC}$ preparations). (B) Cancer cell response to HGF inhibition (AMG102) and c-MET inhibition (cMet Inh) was mediated by ERK1/2 activation. (i) Representative immunoblots for phosphorylated ERK1/2 and GAPDH in AsPC-1 cell lysates collected after exposure of cells to hPSC secretions pretreated with either IgG or AMG102 or c-MET inhibitor (c-Met Inh) for 15 minutes. The top panel shows phosphorylated ERK1/2 while the lower panel indicates GAPDH, used as a loading control. (ii) Graph showing densitometry results [calculated by correction for respective loading controls and expressed as $\%$ of control (co-culture medium)]. Compared to medium control, hPSC secretions significantly increased ERK1/2 phosphorylation (Secr+IgG; ${ }^{*} p<0.05$ vs medium control). This hPSC-induced phosphorylation of ERK1/2 was inhibited with HGF inhibition and c-MET inhibition $\left({ }^{\S} p<0.01 \mathrm{vs}\right.$ Secr+IgG, $n=3$ secretions from separate hPSC preparations). 
Important observations in this model were made in the mice that received all three agents (triple therapy). The greatest reduction of tumor volume was noted in these mice when compared to $\operatorname{IgG}$ treated mice. Notably, metastasis was virtually eliminated in these mice. Striking inhibition of metastasis despite the presence of gemcitabine was surprising since as noted above, gemcitabine alone or in dual combinations did not prevent metastasis and actually increased the stemness and the migratory potential of cancer cells. In contrast, when gemcitabine was part of the triple therapy regimen, stemness of cancer cells in the pancreatic tumors was seen to be significantly reduced.

With regard to EMT as assessed by e-cadherin expression, tumors of mice receiving gemcitabine as a single agent or in dual combination with HGF inhibition or c-MET inhibition exhibited reduction in e-cadherin expression, suggesting increased EMT. This concurs with the observed increase in metastasis in these groups. Interestingly pancreatic tumors of mice receiving triple therapy showed no such decrease in e-cadherin expression, suggesting that EMT was not increased in this group, thus supporting the observed absence of metastasis. However, this effect on EMT in the triple therapy group was not evident with another EMT marker, the transcription factor TWIST. The lack of an inhibitory effect on TWIST expression, despite the significant inhibition of metastasis, in these mice was unexpected. This observation raises the possibility that factors other than TWIST may regulate EMT in pancreatic cancer cells, warranting future work in this area.

We postulate that the striking inhibitory effects of triple therapy on PC progression in our orthotopic model could be explained by a combination of effects that occur along the HGF/c-MET pathway. In untreated PC, stromal PSCs secrete HGF in its precursor form, which is activated by proteases such as urokinase plasminogen activator (uPA). Binding of HGF to its receptor c-MET on cancer cells stimulates several intracellular signalling cascades, which regulate cancer cell functions such as proliferation, migration and apoptosis. In addition, binding of HGF to c-MET increases production of UPA in cancer cells [42], which further activates precursor HGF to active HGF, thus forming a feed forward loop (Figure 9).

Three elements of triple therapy possibly inhibit several steps along the HGF/cMET pathway:

1) $\mathrm{HGF}$ inhibition neutralises PSC-derived active HGF in the ECM surrounding cancer cells, thus preventing HGF/c-MET binding. 2) c-MET inhibition blocks ligandreceptor binding leading to. a) inhibition of downstream intracellular signalling cascades. b) reduction of uPA production by cancer cells, thus preventing further HGF activation (thus inhibiting the positive feedback loop).c) blockade of stemness in cancer cells (given that c-MET is recognized to be a stem cell marker in pancreatic cancer $[30,43])$. d) blockade of the transactivation of the c-MET receptor that is known to occur via other pathways such as the epidermal growth factor receptor (EGFR) [44].

3) Gemcitabine, a nucleoside analogue, causes cancer cell death [45].

The overall outcome of the above effects is to inhibit the well-established bidirectional interaction between PSCs and cancer cells in addition to killing cancer cells, thereby resulting in decreased tumor growth and metastasis.

In summary our study indicates that a novel and an effective therapeutic approach to pancreatic cancer may be achieved with a two-pronged approach that targets not only cancer cells but also stromal cells to interrupt stromal-tumor interactions that facilitate cancer progression. To date, a number of targeted therapies that showed significant promise in pre-clinical studies have failed to translate successfully to the clinical situation [46-49]. We believe this is partly due to the absence of a stromal component in these pre-clinical models. The use of a more biologically relevant model of pancreatic cancer involving both human pancreatic cancer cells and human pancreatic stellate cells increases the potential for our results to be translated to the clinical situation.

\section{MATERIALS AND METHODS}

\section{Reagents}

Reagents include Iscove's Modified Dulbecco's Medium, RePMI Medium 1640, fetal bovine serum, glutamine, and 4,6-diamidino-2-phenylindole (DAPI) from (Life Technologies Corporation, Tullamarine, VIC, Australia); Dulbecco's Modified Eagle's Medium and Xten Hybricell SFM Medium from Thermo Fisher Scientific (Waltham, MA, USA); anti-human alpha smooth muscle actin ( $\alpha$ SMA) antibody, anti-human DCLK1 antibody, from Sigma-Aldrich (St. Louis, MO, USA); anti-human cytokeratin antibody, 3,3diaminobenzidine (DAB) tetrahydrochloride substrate from DAKO (Campbellfield, VIC, Australia); antihuman CD31 antibody, anti-human TWIST antibody from Abcam (Melbourne, VIC, Australia) and antihuman glial fibrillary acidic protein (GFAP) antibody (Millipore, North Ryde, NSW, Australia); Safil 5/0 polyglycolic acid absorbable surgical suture from B. Braun (BellaVista, NSW, Australia); Cell culture inserts $8 \mu \mathrm{M}$ pores (Becton-Dickinson, Bedford, MA, USA); CytoSelect Tumor Transendothelial Migration Assay kit from Cell Biolabs, Inc. (San Diego, CA, USA); Cell Counting Kit-8 (Dojindo Technologies Pty Ltd, Parkville, VIC, Australia) multi-parameter apoptosis kit from Cayman chemicals, (Ann Arbor, MI, USA) Pierce Bicinchoninic Acid (BCA) protein assay kit (Thermo Fisher Scientific Pty Ltd, Scoresby, VIC, Australia). HGF neutralizing antibody, (AMG102/ Rilotumumab) and small molecule inhibitor for c-MET (Compound-A) 
from Amgen Inc. (Amgen Inc., Thousand Oaks, CA, USA), gemcitabine as gemcitabine hydrochloride from Hospira (Mulgrave, VIC, Australia), and c-MET inhibitor 100nM (PHA665752, Tocris Bioscience, Noble Park, VIC, Australia) were used. Antibodies for anti-e-cadherin (Abcam, Melbourne, VIC, Australia), anti-human phospho-p44/42 MAPK (ERK1/2) and total ERK1/2 (Cell Signaling Technology, Danvers, MA, USA) were used.

\section{Orthotopic model of pancreatic cancer (in vivo studies)}

The orthotopic model used for these studies has been described in detail previously $[7,10,14,50]$. Briefly, 6-8 week old female athymic nude mice (BALBc nu/nu) were anaesthetized and an incision made in the left flank followed by exteriorization of the spleen and tail of the pancreas. A mixture of human PC cells (AsPC-1) $1 \times 10^{6}$ + human PSCs $1 \times 10^{6}$ in $50 \mu \mathrm{L}$ PBS was injected into the tail of pancreas. This ratio of PC cells to PSCs was chosen to replicate early cancer development and progression. Seven days after implantation of AsPC1+hPSCs, mice were randomized to receive treatment as detailed below for a further 6 weeks.

\section{Animal grouping ( $n=7$ mice/group)}

Group 1 Control group (IgG/vehicle control). $200 \mu \mathrm{l}$ PBS with isotype IgG twice weekly intraperitoneal (IP) injections and daily oral gavage of soybean oil as vehicle control for Compound-A (small molecule inhibitor for human c-MET) (Group referred to in figures as "IgG") Group 2 AMG102 (monoclonal antibody against human HGF) dissolved in $200 \mu \mathrm{l}$ PBS $300 \mu \mathrm{g}$ IP twice weekly; dose based on our previously published studies $[14,18]$. (Group referred to in figures as " $A$ ") Group 3 Compound-A (small molecule c-MET inhibitor) $60 \mathrm{mg} / \mathrm{kg}$ BW dissolved in soybean oil administered as daily oral gavage; dose based on preliminary dose-response studies establishing the maximally effective and non-toxic dose. (Group referred to in figures as "C") Group 4 Gemcitabine $75 \mathrm{mg} / \mathrm{kg}$ BW IP twice weekly (Group referred to in figures as "G") Group 5 AMG102 + Compound-A $(A+C)$ Group 6 AMG102 + gemcitabine $(\mathrm{A}+\mathrm{G})$ Group 7 c-MET inhibitor + gemcitabine $(\mathrm{C}+\mathrm{G})$ Group 8 AMG102 + c-MET inhibitor + gemcitabine (Triple therapy or CAG).

Pancreatic tumor growth was monitored by palpation. Mice were sacrificed after six weeks of treatment. Primary tumors were resected and their size measured using digital Vernier callipers by two separate observers. Tumor volume was calculated to two decimal points, according to an

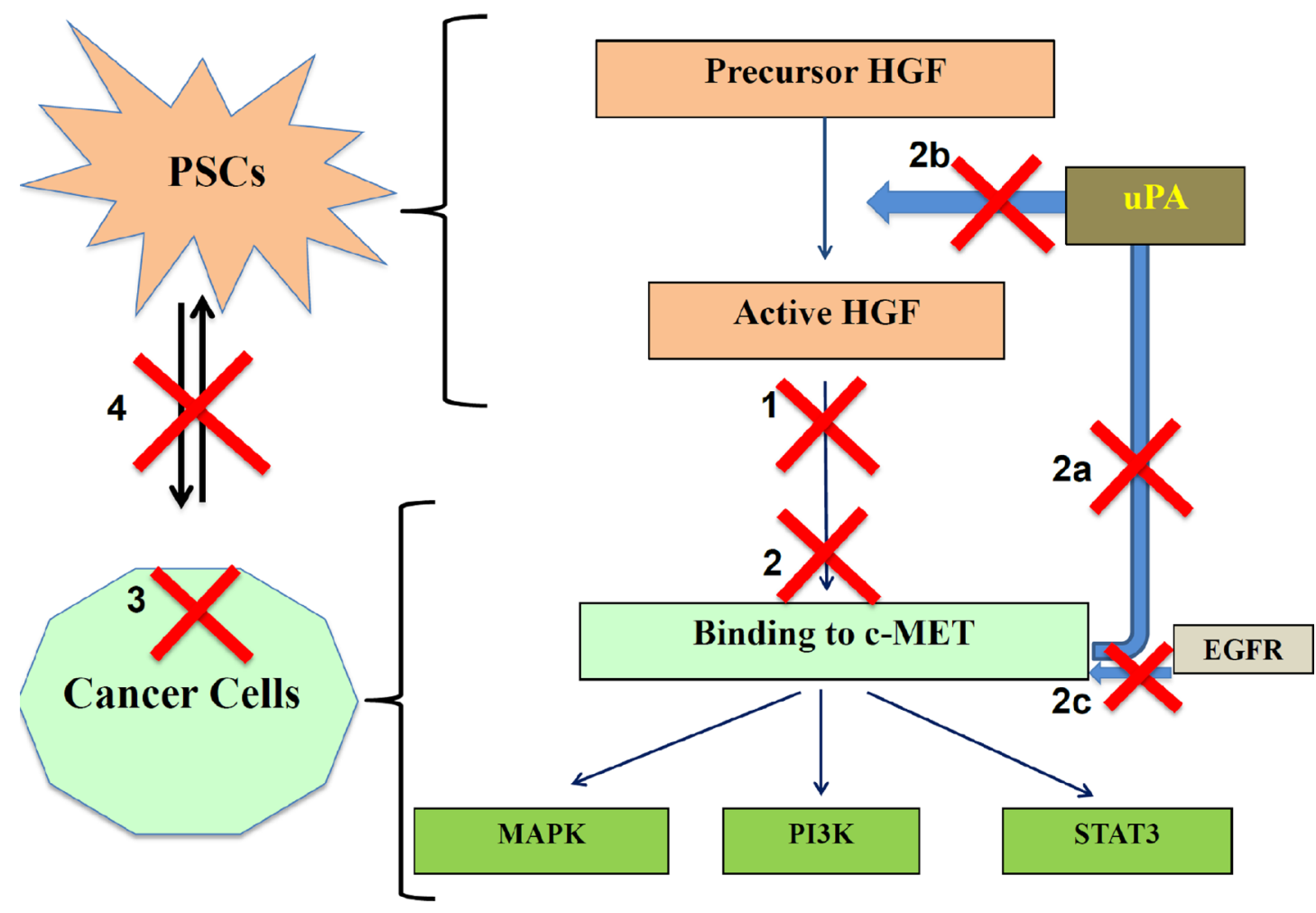

Figure 9: Schematic depicting the possible mechanisms involved in effects of triple therapy on PC progression. Possible actions of these compounds are shown as numbered red crosses in the figure. 1. AMG102 neutralizes active HGF, reducing HGF/cMET binding. 2. c-MET inhibitor works by preventing binding of ligand HGF to the receptor c-MET directly by inhibiting the pathway. Additionally, c-MET inhibitor acts by: 2a) Reducing uPA production by cancer cells. 2b) Inhibiting further HGF activation. 2 c) Preventing transactivation of c-MET by other pathways such as EGFR. 3. Gemcitabine causes cancer cell death. 4. Overall the bidirectional interactions between PSCs and cancer cells are significantly reduced. 
established formula [1/2 (length $\mathrm{x}$ breadth $\mathrm{x}$ width) [51]. Tumor tissue was then dissected out for further processing. The abdominal cavity, mesentery, spleen, liver and lungs were examined and scored according to the presence or absence of visible metastatic nodules. Metastatic nodules were collected, fixed in formalin and processed for H\&E staining. Tumors were compared with respect to size and weight. Tumors were stained with H\&E for morphology, while collagen deposition was assessed by Sirius red staining as described previously [10, 28]. Primary tumor sections were also immunostained for cytokeratin (cancer cell marker), DCLK1 (stem cell marker), TWIST (EMT marker), and CD31 (endothelial cell marker).

\section{Expression of $\alpha \mathrm{SMA}$, cytokeratin, CD31, DCLK1 \& TWIST in primary tumors}

Paraffin sections ( $4 \mu \mathrm{m}$ thickness) of primary tumors were dewaxed and rehydrated. Following heat-mediated antigen retrieval, tumor sections were incubated overnight at $4^{\circ} \mathrm{C}$ with respective primary antibodies as described previously [14]. Immunostaining of tumor sections for aSMA (1:800), cytokeratin (1:75), CD31 (1:50), DCLK1 (1:500), and TWIST (1:500) were performed using anti-human primary antibodies in provided dilutions in blocking buffer. This was followed by incubation with respective HRP-labelled secondary antibodies. Subsequently, the sections were incubated with DAB substrate and the signal was visualized by chromogen.

For morphometric analyses, ten fields were selected randomly (by observers blinded to treatment groups) for each tissue section and positive stained (brown) cells were counted, as described previously [14, 28]. Endothelial cells in primary tumors were identified by immunostaining for the endothelial cell marker CD31. Cells expressing stem cells and EMT characteristics were assessed by immunostaining the tumor sections for stem cell marker DCLK1 and transcription factor TWIST respectively. Results were analysed as the total number of positive cells in all 10 selected fields and expressed as \% of control (i.e. tumor sections from IgG treated mice).

\section{Immunoblotting on tumor homogenates}

Tumor samples that were snap frozen were homogenized by mechanical disruption using a mortar and pestle in presence of liquid nitrogen in RIPA buffer with protease and phosphatase inhibitors. Proteins were quantified using bicinchoninic acid assay (BCA assay) according to Manufacturer's instructions. Homogenates were then subjected to immunoblotting as detailed below for assessment of e-cadherin expression.

Proteins were separated using 10\% SDS polyacrylamide gels and transferred onto nitrocellulose membranes. Membranes were blocked for one hour in 5\% skim milk in TRIS buffered saline with Tween-20 (TTBS), followed by overnight incubation at $4{ }^{\circ} \mathrm{C}$ anti-rabbit e-cadherin 1:500. Following a wash protocol, membranes were incubated for one hour at room temperature with an HRP-conjugated goat anti-rabbit secondary antibody (DAKO Australia Pty Ltd, Kingsgrove, NSW, Australia), diluted 1:2000 in blocking buffer. Target proteins were detected using the Bio-Rad ECL kit (BioRad, Philadelphia, PA, USA) as described previously [14]. Loading control total ERK1/2 was determined by incubating overnight at $4^{\circ} \mathrm{C}$ with anti-rabbit ERK1/2 antibody (Cell Signaling Technology, Danvers, MA, USA) diluted 1:1000 in TTBS. Densitometry readings for e-cadherin were corrected to their respective loading controls. Results are expressed as \% of control (i.e. tumor homogenates from IgG treated tumors).

\section{In vitro studies: cell culture}

AsPC1 cells were cultured and hPSCs were isolated and cultured as previously published by us [14].

\section{Indirect co-culture experiments}

To study the role of the HGF/c-MET pathway in the interactions between PSCs and cancer cells in vitro, indirect co-cultures were set up which involved incubation of cancer cells with conditioned medium from PSCs.

\section{Collection of conditioned medium from PSCs and HGF measurement}

As described previously, PSCs were passaged by trypsinization when $70-80 \%$ confluence was reached. Conditioned media (hPSC secretions) used for experiments were collected from hPSCs. Media $(0.1 \%$ SFM4MAb for proliferation and migration assays or $0 \%$ IMDM for apoptosis assays) were collected, centrifuged at $1,000 \mathrm{~g}$ for $10 \mathrm{~min}$ at $4^{\circ} \mathrm{C}$, and the supernatant was concentrated with Centricon YM3 filters (Millipore). HGF in hPSC secretions was quantified using a human HGF Quantikine ELISA Kit (R\&D Systems) according to the manufacturer's instructions as described previously [19]. The secretions were stored at $-80^{\circ} \mathrm{C}$ until used for functional assays. For assays that required pretreated secretions, appropriate dilution of secretions was performed with co-culture medium so as to standardize HGF to a concentration of 2000pg HGF/ml. This concentration was used since it reflects the actual amount produced by hPSCs over 24 hours $[14,19]$.

\section{Pretreatmeant of hPSC secretions and cancer cells}

Secretions from hPSCs $(n=5)$ that had been standardized to $2000 \mathrm{pg} \mathrm{HGF} / \mathrm{mL}$ were pretreated for one hour at $37^{\circ} \mathrm{C}$ with either $60 \mu \mathrm{g} / \mathrm{mL}$ AMG102 (HGF neutralizing antibody) or $60 \mu \mathrm{g} / \mathrm{mL}$ IgG (isotype control 
for AMG102). Similarly cancer cells were pre-exposed to the c-MET inhibitor $100 \mathrm{nM}$ (PHA665752) for one hour at $37^{\circ} \mathrm{C}$. Following this pretreatment of cancer cells, hPSC secretions \pm gemcitabine $(300 \mu \mathrm{g} / \mathrm{mL})$ were added to the cells. Therefore the experimental set up included cancer cells treated with PSC secretions in presence and absence of either AMG102 or c-MET inhibitor or gemcitabine.

The concentrations of HGF antibody, c-MET inhibitor and gemcitabine were calculated to correspond to the in vivo doses used in these studies, assuming the total circulating volume of a $20 \mathrm{gm}$ mouse to be $5 \mathrm{~mL}$ as reported in our previous publication [14].

Note: For our in vitro studies a commercially available c-MET inhibitor (PHA665752) that has been widely used in published literature was employed [37, 38] since it is water soluble. Compound-A used in our in vivo model, is soluble only in soybean oil and therefore could not be used in culture medium.

\section{Proliferation of AsPC-1 cells in response to indirect co-culture}

The effects of HGF inhibition on AsPC-1 proliferation were measured using the Cell Counting Kit-8. AsPC-1 cells were seeded at a density of 5000 cells/ well in a 96 well plate. The following day, culture medium was removed and wells were rinsed twice with warm PBS. $200 \mu \mathrm{L}$ of pretreated hPSC secretions (see above) were applied to each well. After incubation for 24 hours at $37^{\circ} \mathrm{C}$ the assay was performed according to Manufacturer's instructions. This assay uses a tetrazolium salt, which produces a water-soluble formazan when reduced. The amount of formazan produced is directly proportional to the number of living cells. The optical density of the wells was determined at $450 \mathrm{~nm}$.

\section{Migration of AsPC-1 cells in response to indirect co-culture}

AsPC-1 cell migration was assessed using a modified Boyden chamber method as published by our Group previously $[10,52]$ according to Manufacturer's instructions. Number of migrated cancer cells was assessed by recording fluorescence $(480 \mathrm{~nm} / 520 \mathrm{~nm})$ on the plate using a SpectraMax M2e micro plate reader (Molecular Devices, Sunnyvale, CA, USA).

\section{Apoptosis of AsPC-1 cells in response to indirect co-culture}

AsPC-1 cells were seeded at a density of 15,000 cells/well in a 96-well opaque plate and cultured in serumfree IMDM overnight to induce apoptosis. Cells were then incubated with hPSC secretions (pre-treated as described above) for 24 hours and apoptosis was assessed by staining for cell based Annexin-V tagged with FITC as per the Multi-parameter Apoptosis Kit instructions (Cayman Chemicals, Ann Arbor, MI, USA). Apoptosis was assessed by recording fluorescence $(485 \mathrm{~nm} / 535 \mathrm{~nm})$ on the plate using a SpectraMax M2e micro plate reader (Molecular Devices, Sunnyvale, CA, USA).

\section{Immunoblotting for signalling pathways (c-MET phosphorylation and MAPK activation)}

AsPC-1 cells were exposed to one of the following treatments for 15 minutes: i) co-culture medium; ii) hPSC secretions + IgG; iii) hPSC secretions + AMG102, iv) hPSC secretions + c-MET inhibitor (as described above, using secretions from $n=3$ different hPSCs preparations). After 15 minutes exposure, secretions were removed, cells were lysed and protein quantified using bicinchoninic acid assay (BCA assay) according to Manufacturer's instructions. Lysates were then subjected to immunoblotting as detailed below for assessment of MAPK activation. Similarly lysates from AsPC-1 cells were collected for assessment of c-MET activation after treatment for 10 minutes.

Lysed proteins were separated using 10\% SDS polyacrylamide gels and transferred onto nitrocellulose membranes. Membranes were blocked for one hour in $5 \%$ skim milk in TRIS buffered saline with Tween-20 (TTBS), followed by overnight incubation at $4{ }^{\circ} \mathrm{C}$ anti-rabbit phospho-MET (Tyr1234/1235) (D26, Cell Signaling Technology, Danvers, MA, USA) 1:1000, antirabbit total MET (D1C2, Cell Signaling Technology, Danvers, MA, USA) 1:1000 and anti-mouse GAPDH (Abcam, Melbourne, VIC, Australia) 1:50000. Overnight incubation with phospho-p44/42 MAPK (ERK1/2) (Cell Signaling Technology, Danvers, MA, USA) rabbit mAb diluted 1:1000 in TTBS with 5\% BSA (bovine serum albumin) was performed to determine MAPK activation. Following a wash, membranes were incubated for one hour at room temperature with an HRP-conjugated goat anti-rabbit secondary antibody (DAKO Australia Pty Ltd, Kingsgrove, NSW, Australia), diluted 1:2000 in blocking buffer. Target proteins were detected using the Bio-Rad ECL kit (Bio-Rad, Philadelphia, PA, USA) as described previously [14]. Loading control GAPDH was determined by incubating overnight at $4^{\circ} \mathrm{C}$ with anti-mouse GAPDH antibody (Abcam, Melbourne, VIC, Australia) diluted 1:50000 in TTBS. Densitometry readings for phosphorylated ERK1/2 and c-MET were corrected for their loading controls. Results are expressed as \% of control (i.e. expression in cells treated with coculture medium as control).

\section{Statistical analysis}

Data are expressed as mean \pm SEM. Student's $t$-test, one-way analysis of variance with Tukey's post hoc test, or Fisher's exact tests were applied as appropriate. Analyses 
were performed using GraphPad Prism 6.00 for Mac OS X (GraphPad Software, San Diego, CA, USA).

\section{Ethics approvals}

The South Eastern Sydney Local Health District Human Research Ethics Committee [13/023 (HREC/13/ POWH/65)] and the Animal Care and Ethics Committee (ACEC12/102B) of The University of New South Wales, Sydney, Australia, approved these studies.

\section{ACKNOWLEDGMENTS}

This work was supported by a grant from the Cancer Council of New South Wales (RG-13-01) and Hirshberg Foundation for Pancreatic Cancer Research, USA. AMG102, isotype IgG and compound-A were kindly provided by Amgen Inc. under an MTA.

\section{REFERENCES}

1. Kleeff J, Korc M, Apte M, La Vecchia C, Johnson CD, Biankin AV, Neale RE, Tempero M, Tuveson DA, Hruban RH, Neoptolemos JP. Pancreatic cancer. Nat Rev Dis Primers. 2016; 2:16022.

2. Apte MV, Wilson JS, Lugea A, Pandol SJ. A starring role for stellate cells in the pancreatic cancer microenvironment. Gastroenterology. 2013; 144:1210-9.

3. Apte MV, Xu Z, Pothula S, Goldstein D, Pirola RC, Wilson JS. Pancreatic cancer: The microenvironment needs attention too! Pancreatology. 2015; 15:S32-8.

4. Xu Z, Pothula SP, Wilson JS, Apte MV. Pancreatic cancer and its stroma: a conspiracy theory. World J Gastroenterol. 2014; 20:11216-29.

5. Apte MV, Park S, Phillips PA, Santucci N, Goldstein D, Kumar RK, Ramm GA, Buchler M, Friess H, McCarroll JA, Keogh G, Merrett N, Pirola R, et al. Desmoplastic reaction in pancreatic cancer: role of pancreatic stellate cells. Pancreas. 2004; 29:179-87.

6. Apte MV, Wilson JS. Dangerous liaisons: pancreatic stellate cells and pancreatic cancer cells. J Gastroenterol Hepatol. 2012; 27:69-74.

7. Hwang RF, Moore T, Arumugam T, Ramachandran V, Amos KD, Rivera A, Ji B, Evans DB, Logsdon CD. Cancerassociated stromal fibroblasts promote pancreatic tumor progression. Cancer Res. 2008; 68:918-26.

8. Masamune A, Kikuta K, Watanabe T, Satoh K, Hirota M, Shimosegawa T. Hypoxia stimulates pancreatic stellate cells to induce fibrosis and angiogenesis in pancreatic cancer. Am J Physiol Gastrointest Liver Physiol. 2008; 295:G709-17.

9. Phillips PA, Wu MJ, Kumar RK, Doherty E, McCarroll JA, Park S, Pirola RC, Wilson JS, Apte MV. Cell migration: a novel aspect of pancreatic stellate cell biology. Gut. 2003; 52:677-82.
10. Xu Z, Vonlaufen A, Phillips PA, Fiala-Beer E, Zhang X, Yang L, Biankin AV, Goldstein D, Pirola RC, Wilson JS, Apte MV. Role of pancreatic stellate cells in pancreatic cancer metastasis. The American journal of pathology. 2010; 177:2585-96.

11. Bachem MG, Schunemann M, Ramadani M, Siech M, Beger H, Buck A, Zhou S, Schmid-Kotsas A, Adler G. Pancreatic carcinoma cells induce fibrosis by stimulating proliferation and matrix synthesis of stellate cells. Gastroenterology. 2005; 128:907-21.

12. Erkan M, Reiser-Erkan C, Michalski CW, Deucker S, Sauliunaite D, Streit S, Esposito I, Friess H, Kleeff J. Cancer-stellate cell interactions perpetuate the hypoxiafibrosis cycle in pancreatic ductal adenocarcinoma. Neoplasia. 2009; 11:497-508.

13. Habisch H, Zhou S, Siech M, Bachem MG. Interaction of Stellate Cells with Pancreatic Carcinoma Cells. Cancers. 2010; 2:1661-82.

14. Pothula SP, Xu Z, Goldstein D, Biankin AV, Pirola RC, Wilson JS, Apte MV. Hepatocyte growth factor inhibition: a novel therapeutic approach in pancreatic cancer. Br J Cancer. 2016; 114:269-80.

15. Pothula SP, Xu Z, Goldstein D, Pirola RC, Wilson JS, Apte MV. Key role of pancreatic stellate cells in pancreatic cancer. Cancer Lett. 2016; 381:194-200.

16. Watanabe S, Kishimoto T, Yokosuka O. Hepatocyte growth factor inhibits anoikis of pancreatic carcinoma cells through phosphatidylinositol 3-kinase pathway. Pancreas. 2011; 40:608-14.

17. Matsushita A, Gotze T, Korc M. Hepatocyte growth factor-mediated cell invasion in pancreatic cancer cells is dependent on neuropilin-1. Cancer Res. 2007; 67:10309-16.

18. Arun SJ, Xu Z, Fiala-Beer E, Yang L, Phillips PA, Goldstein D, Biankin A, Pirola R, Wilson JS, Apte MV. Hepatocyte Growth Factor: A Potential Therapeutic Target in Pancreatic Cancer. Pancreas. 2011; 40:1310-1.

19. Patel MB, Pothula SP, Xu Z, Lee AK, Goldstein D, Pirola RC, Apte MV, Wilson JS. The role of the hepatocyte growth factor/c-MET pathway in pancreatic stellate cellendothelial cell interactions: antiangiogenic implications in pancreatic cancer. Carcinogenesis. 2014; 35:1891-900.

20. Qian LW, Mizumoto K, Maehara N, Ohuchida K, Inadome $\mathrm{N}$, Saimura $\mathrm{M}$, Nagai $\mathrm{E}$, Matsumoto $\mathrm{K}$, Nakamura T, Tanaka M. Co-cultivation of pancreatic cancer cells with orthotopic tumor-derived fibroblasts: fibroblasts stimulate tumor cell invasion via HGF secretion whereas cancer cells exert a minor regulative effect on fibroblasts HGF production. Cancer Lett. 2003; 190:105-12.

21. Jiang WG, Martin TA, Parr C, Davies G, Matsumoto K, Nakamura T. Hepatocyte growth factor, its receptor, and their potential value in cancer therapies. Crit Rev Oncol Hematol. 2005; 53:35-69.

22. Hage C, Rausch V, Giese N, Giese T, Schonsiegel F, Labsch S, Nwaeburu C, Mattern J, Gladkich J, Herr I. The 
novel c-Met inhibitor cabozantinib overcomes gemcitabine resistance and stem cell signaling in pancreatic cancer. Cell Death Dis. 2013; 4:e627.

23. Hermann PC, Huber SL, Herrler T, Aicher A, Ellwart JW, Guba M, Bruns CJ, Heeschen C. Distinct populations of cancer stem cells determine tumor growth and metastatic activity in human pancreatic cancer. Cell Stem Cell. 2007; 1:313-23.

24. Quint K, Tonigold M, Di Fazio P, Montalbano R, Lingelbach S, Ruckert F, Alinger B, Ocker M, Neureiter D. Pancreatic cancer cells surviving gemcitabine treatment express markers of stem cell differentiation and epithelial-mesenchymal transition. Int J Oncol. 2012; 41:2093-102.

25. Simeone DM. Pancreatic cancer stem cells: implications for the treatment of pancreatic cancer. Clin Cancer Res. 2008; 14:5646-8.

26. Bussolino F, Di Renzo MF, Ziche M, Bocchietto E, Olivero M, Naldini L, Gaudino G, Tamagnone L, Coffer A, Comoglio PM. Hepatocyte growth factor is a potent angiogenic factor which stimulates endothelial cell motility and growth. J Cell Biol. 1992; 119:629-41.

27. Grant DS, Kleinman HK, Goldberg ID, Bhargava MM, Nickoloff BJ, Kinsella JL, Polverini P, Rosen EM. Scatter factor induces blood vessel formation in vivo. Proceedings of the National Academy of Sciences of the United States of America. 1993; 90:1937-41.

28. Vonlaufen A, Joshi S, Qu C, Phillips PA, Xu Z, Parker NR, Toi CS, Pirola RC, Wilson JS, Goldstein D, Apte MV. Pancreatic stellate cells: partners in crime with pancreatic cancer cells. Cancer Res. 2008; 68:2085-93.

29. Brandes F, Schmidt K, Wagner C, Redekopf J, Schlitt HJ, Geissler EK, Lang SA. Targeting cMET with INC280 impairs tumour growth and improves efficacy of gemcitabine in a pancreatic cancer model. BMC Cancer. 2015; 15:71.

30. Li C, Wu JJ, Hynes M, Dosch J, Sarkar B, Welling TH, Pasca di Magliano M, Simeone DM. c-Met is a marker of pancreatic cancer stem cells and therapeutic target. Gastroenterology. 2011; 141:2218-27.e5.

31. Byun JY, Youn YS, Lee YJ, Choi YH, Woo SY, Kang JL. Interaction of apoptotic cells with macrophages upregulates COX-2/PGE2 and HGF expression via a positive feedback loop. Mediators Inflamm. 2014; 2014:463524.

32. Watson GA, Zhang X, Stang MT, Levy RM, Queiroz de Oliveira PE, Gooding WE, Christensen JG, Hughes SJ. Inhibition of c-Met as a therapeutic strategy for esophageal adenocarcinoma. Neoplasia. 2006; 8:949-55.

33. Yang Y, Wislez M, Fujimoto N, Prudkin L, Izzo JG, Uno F, Ji L, Hanna AE, Langley RR, Liu D, Johnson FM, Wistuba I, Kurie JM. A selective small molecule inhibitor of c-Met, PHA-665752, reverses lung premalignancy induced by mutant K-ras. Mol Cancer Ther. 2008; 7:952-60.

34. Matsumura A, Kubota T, Taiyoh H, Fujiwara H, Okamoto K, Ichikawa D, Shiozaki A, Komatsu S, Nakanishi M, Kuriu Y, Murayama Y, Ikoma H, Ochiai T, et al. HGF regulates
VEGF expression via the c-Met receptor downstream pathways, PI3K/Akt, MAPK and STAT3, in CT26 murine cells. Int J Oncol. 2013; 42:535-42.

35. Bauer TW, Somcio RJ, Fan F, Liu W, Johnson M, Lesslie DP, Evans DB, Gallick GE, Ellis LM. Regulatory role of c-Met in insulin-like growth factor-I receptormediated migration and invasion of human pancreatic carcinoma cells. Mol Cancer Ther. 2006; 5:1676-82.

36. Ucar DA, Magis AT, He DH, Lawrence NJ, Sebti SM, Kurenova E, Zajac-Kaye M, Zhang J, Hochwald SN. Inhibiting the interaction of cMET and IGF-1R with FAK effectively reduces growth of pancreatic cancer cells in vitro and in vivo. Anticancer Agents Med Chem. 2013; 13:595-602.

37. Christensen JG, Schreck R, Burrows J, Kuruganti P, Chan E, Le P, Chen J, Wang X, Ruslim L, Blake R, Lipson KE, Ramphal J, Do S, et al. A selective small molecule inhibitor of c-Met kinase inhibits c-Met-dependent phenotypes in vitro and exhibits cytoreductive antitumor activity in vivo. Cancer Res. 2003; 63:7345-55.

38. Ma PC, Schaefer E, Christensen JG, Salgia R. A selective small molecule c-MET Inhibitor, PHA665752, cooperates with rapamycin. Clin Cancer Res. 2005; 11:2312-9.

39. Zhao Y, Zhao J, Mialki RK, Wei J, Spannhake EW, Salgia R, Natarajan V. Lipopolysaccharide-induced phosphorylation of c-Met tyrosine residue 1003 regulates c-Met intracellular trafficking and lung epithelial barrier function. Am J Physiol Lung Cell Mol Physiol. 2013; 305:L56-63.

40. Qu D, Johnson J, Chandrakesan P, Weygant N, May R, Aiello N, Rhim A, Zhao L, Zheng W, Lightfoot S, Pant S, Irvan J, Postier $\mathrm{R}$, et al. Doublecortin-like kinase 1 is elevated serologically in pancreatic ductal adenocarcinoma and widely expressed on circulating tumor cells. PLoS One. 2015; 10:e0118933.

41. Bailey JM, Alsina J, Rasheed ZA, McAllister FM, Fu YY, Plentz R, Zhang H, Pasricha PJ, Bardeesy N, Matsui W, Maitra A, Leach SD. DCLK1 marks a morphologically distinct subpopulation of cells with stem cell properties in preinvasive pancreatic cancer. Gastroenterology. 2014; 146:245-56.

42. Bauer TW, Liu W, Fan F, Camp ER, Yang A, Somcio RJ, Bucana CD, Callahan J, Parry GC, Evans DB, Boyd DD, Mazar AP, Ellis LM. Targeting of urokinase plasminogen activator receptor in human pancreatic carcinoma cells inhibits c-Met- and insulin-like growth factor-I receptormediated migration and invasion and orthotopic tumor growth in mice. Cancer Res. 2005; 65:7775-81.

43. Suzuki A, Nakauchi H, Taniguchi H. Prospective isolation of multipotent pancreatic progenitors using flow-cytometric cell sorting. Diabetes. 2004; 53:2143-52.

44. Dulak AM, Gubish CT, Stabile LP, Henry C, Siegfried JM. HGF-independent potentiation of EGFR action by c-Met. Oncogene. 2011; 30:3625-35.

45. Plunkett W, Huang P, Xu YZ, Heinemann V, Grunewald R, Gandhi V. Gemcitabine: metabolism, mechanisms of action, and self-potentiation. Semin Oncol. 1995; 22:3-10. 
46. Beatty GL, Chiorean EG, Fishman MP, Saboury B, Teitelbaum UR, Sun W, Huhn RD, Song W, Li D, Sharp LL, Torigian DA, O'Dwyer PJ, Vonderheide RH. CD40 agonists alter tumor stroma and show efficacy against pancreatic carcinoma in mice and humans. Science. 2011; 331:1612-6.

47. Provenzano PP, Cuevas C, Chang AE, Goel VK, Von Hoff DD, Hingorani SR. Enzymatic targeting of the stroma ablates physical barriers to treatment of pancreatic ductal adenocarcinoma. Cancer Cell. 2012; 21:418-29.

48. Olive KP, Jacobetz MA, Davidson CJ, Gopinathan A, McIntyre D, Honess D, Madhu B, Goldgraben MA, Caldwell ME, Allard D, Frese KK, Denicola G, Feig C, et al. Inhibition of Hedgehog signaling enhances delivery of chemotherapy in a mouse model of pancreatic cancer. Science. 2009; 324:1457-61.

49. Jacobetz MA, Chan DS, Neesse A, Bapiro TE, Cook N, Frese KK, Feig C, Nakagawa T, Caldwell ME, Zecchini HI, Lolkema MP, Jiang P, Kultti A, et al. Hyaluronan impairs vascular function and drug delivery in a mouse model of pancreatic cancer. Gut. 2013; 62:112-20.
50. Vonlaufen A, Phillips PA, Xu Z, Goldstein D, Pirola RC, Wilson JS, Apte MV. Pancreatic stellate cells and pancreatic cancer cells: an unholy alliance. Cancer Res. 2008; 68:7707-10.

51. Xu Z, Vonlaufen A, Phillips PA, Fiala-Beer E, Zhang X, Yang L, Biankin AV, Goldstein D, Pirola RC, Wilson JS, Apte MV. Role of pancreatic stellate cells in pancreatic cancer metastasis. Am J Pathol. 2010; 177:2585-96.

52. Lee AT, Xu Z, Pothula SP, Patel MB, Pirola RC, Wilson JS, Apte MV. Alcohol and Cigarette Smoke Components Activate Human Pancreatic Stellate Cells: Implications for the Progression of Chronic Pancreatitis. Alcohol Clin Exp Res. 2015; 39:2123-33. 